\title{
LA ARQUITECTURA DOMÉSTICA ROMANA EN LA ALCUDIA DE ELCHE. LA DOMUS 5-F ${ }^{1}$
}

\author{
DOMESTIC ROMAN ARCHITECTURE IN LA ALCUDIA OF ELCHE. THE DOMUS 5-F
}

\author{
JULIA SARABIA BAUTISTA \\ Universitat de Alicante \\ VÍCTOR CAÑAVATE CASTEJÓN \\ Parque Arqueológico Tolmo de Minateda
}

Recepción: 14-07-2009; Aceptación: 04-08-2009

Hace ya más de una década que se constituyó la Fundación Universitaria de Investigación Arqueológica La Alcudia, como un intento por parte del nuevo equipo científico encabezado por Lorenzo Abad y Mercedes Tendero de promover la modernización de las estructuras y de los métodos de actuación en un yacimiento que, si bien es cierto ha gozado de una amplia y conocidísima historiografía desde la segunda mitad del siglo XIX, no siempre ha sido objeto de una metodología de estudio del todo adecuada, estableciéndose de forma inamovible algunos convencionalismos estratigráficos e históricos que en muchas ocasiones no se han reflejado en la realidad arqueológica.

Desde ese momento se han realizado algunas actuaciones puntuales que han permitido obtener una «estratigrafía recuperada» de aquellos sectores excavados de antiguo y se han planteado nuevas intervenciones en otras zonas del yacimiento que aportan una actualización de los datos arqueológicos en este enclave ${ }^{2}$.

En este sentido debemos destacar dos excavaciones realizadas en antiguos sectores ya exhumados parcialmente en décadas anteriores y que se han convertido en un ejemplo de las posibilidades de reestudio que ofrece La Alcudia todavía. Uno de estos sectores es el que tra-

1. Los estudios que están en la base de este trabajo se han realizado en el marco del proyecto HUM-2006-09874/Hist: Un proceso de romanización comparada: los casos de Ilici y Elo, Proyecto de Investigación y Desarrollo Tecnológico del Ministerio de Educación y Ciencia

2. Además de estas nuevas actuaciones arqueológicas con una metodología renovada, han salido a la luz algunas publicaciones que aportan nuevos datos interpretativos sobre algunos de los restos arqueológicos más emblemáticos del yacimiento. De entre todos ellos destacan dos por su gran aportación, la obra de Gabriel Lara Vives sobre «El templo de Juno de Ilici» (Lara, 2005) y la de Roberto Lorenzo Pérez de San Román sobre «L'Alcúdia d'Elx a l'Antiguitat tardana (segles V-VIII)» (Lorenzo, 2006). dicionalmente se ha venido conociendo como la «muralla tardorromana», atribuida en la historiografía a la reconstrucción de la ciudad tras las invasiones francas del siglo III d.C.

Gracias a un estudio realizado en 1999, se pudo ver cómo en realidad se trataba del muro exterior de un recinto perimetral que englobaba un conjunto termal fechado a mediados del siglo I d.C. (Abad, Moratalla y Tendero, 2000), asociado con toda probabilidad a unas habitaciones calefactadas con hypocausta descubiertas por Pedro Ibarra en las inmediaciones de ese lugar a principios del siglo XX (Ibarra, 1926).

La otra intervención a destacar en esta nueva fase de estudio del yacimiento se realizó en las conocidas como «casas ibéricas», situadas al norte, donde se conserva una calle y varias habitaciones interpretadas tradicionalmente como contextos domésticos propios del oppidum ibérico (Fig. 1). En una de esas habitaciones, conocida como «la tienda del alfarero» (Sala, 1992), apareció un conjunto de materiales con una cronología tardorrepublicana que llevaron a adscribir a esta fase todas las estructuras aparecidas a la misma cota (Abad, e.p.).

En un corte abierto al oeste de estas casas la secuencia estratigráfica muestra interrupciones que contradicen una de las hipótesis más establecidas en los estudios tradicionales del yacimiento, la de que todos los estratos documentados en éste presentan una misma secuencia ininterrumpida que va desde el estrato $H$, perteneciente a los contextos neolíticos o del bronce final, hasta el estrato A de época visigoda e islámica (Ramos Fernández, 1975) ${ }^{3}$.

3. Esta secuencia está basada en la propuesta anteriormente establecida por Alejandro Ramos Folqués en la década de los sesenta (Ramos Folqués, 1956, 1962 y 1966), donde se identificaban seis niveles denominados primero con letras y más tarde con números romanos. Será ya en los años setenta cuando Rafael Ramos Fernández vuelva a readaptar la misma 


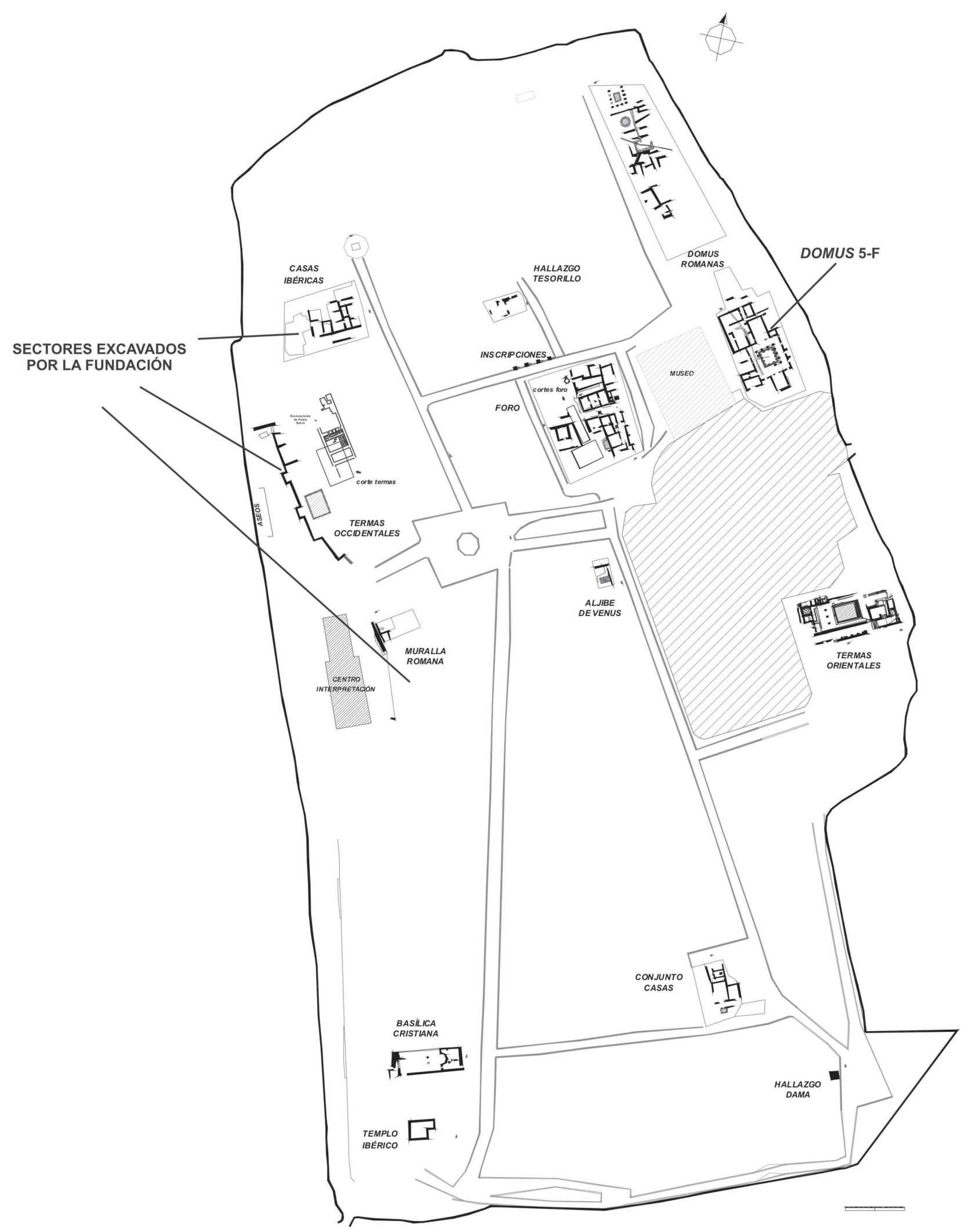

Figura 1: Planimetría general de La Alcudia con los sectores excavados. 
Durante estos trabajos de normalización estratigráfica, además de documentar algunos basureros de época visigoda que demuestran la existencia de niveles de esta fase en un yacimiento en el que por lo general han pasado desapercibidas estas estructuras tardías ${ }^{4}$, también se observó cómo en época altoimperial la orientación de algunas estructuras es diferente a la de los contextos ibéricos, lo que tal vez pueda ponerse en relación con el momento de construcción de las termas y quizá también con una remodelación del urbanismo de la ciudad en época flavia (Abad, e.p.).

En este sentido es en el que queremos hacer nuestra pequeña aportación, ya que tradicionalmente esta remodelación urbana altoimperial se planteó en parte gracias a las evidencias arquitectónicas constatadas en algunos de los ambientes domésticos romanos. Nos referimos sobre todo a las domus excavadas en la zona nororiental del yacimiento conocidas como 3-F y 5-F que, a pesar de que su construcción original parece realizarse sobre los restos de otros ambientes de la ciudad ibérica cuando ésta consigue el rango de colonia, no será hasta mediados del siglo I d.C. cuando aparezcan los elementos que definen una casa típicamente romana, con una arquitectura que parece mantenerse inalterable hasta el siglo III d.C., cuando llegan los invasores francos (Ramos Fernández, 1991, 71). Este tipo de afirmaciones basadas en una estratigrafía, que como ya hemos visto resulta estar algo idealizada, desestiman en gran medida otros procesos menores de evolución de la vivienda que podrían extraerse en parte profundizando en el análisis de otros indicadores cronológicos, como es el caso de los programas decorativos de la casa, o planteando nuevas intervenciones en la zona para documentar todos los procesos postdeposicionales sufridos en la dilatada vida de esta domus.

En este caso nos centraremos en un nuevo análisis de la estratigrafía publicada sobre la excavación de una de estas domus, la 5-F, e intentaremos ver hasta qué punto se corresponden las fases propuestas con otro tipo de indicadores cronológicos que, en un mundo tan estandarizado como el romano, pueden aportarnos datos muy interesentes sobre la evolución arquitectónica sufrida en este ambiente.

añadiendo dos niveles más y utilizando de nuevo letras (Ramos Fernández, 1975).

4. Hemos de tener en cuenta que en época visigoda la ciudad de Ilici albergó una sede episcopal y tras la ocupación islámica a comienzos del siglo VIII fue una de las ciudades del Pacto de Teodomiro (Gutiérrez, 1996), algo que parecía no reflejarse del todo en la realidad arqueológica de La Alcudia exhumada hasta hace unos años y que probablemente responda al escaso interés de la historiografía tradicional por estos contextos.

\section{LA SECUENCIA ESTRATIGRÁFICA DE LA DO- $M U S^{5}$}

Al igual que en el resto de sectores exhumados, durante la excavación de la domus 5-F se individualizaron 8 «estratos» infrapuestos al nivel agrícola. Nos gustaría aclarar que lo que aquí se entiende por «estrato» no es estrictamente el concepto aceptado para la metodología arqueológica actual, ya que cada uno de esos paquetes de derrumbe y pavimentación a los que hacen referencia y que se engloban en un único estrato deberían haber sido individualizados para así identificar, dentro de la secuencia cronológica de cada fase, cada uno de los procesos postdeposicionales acontecidos y poder averiguar en qué momento concreto ocurre cada hecho dentro de esa secuencia (la construcción, el uso, el abandono y la destrucción de las estructuras).

Como ya mencionábamos al comienzo de este artículo, esos ocho estratos se identifican con una secuencia de letras donde la A hace referencia a los niveles arqueológicos más modernos documentados en el yacimiento, por lo que tendríamos:

Un estrato A perteneciente a los contextos visigodos, donde se englobaban paquetes de derrumbe y pavimentaciones asociadas a muros con aparejo de cantos rodados, piedra de mediano y pequeño tamaño y material cerámico de construcción reempleado. En los niveles de frecuentación de este estrato, se recuperaron pavimentos de cal sobre tierra apisonada y de tierra batida endurecida (Ramos Fernández, 1983, 147).

Parece que las estructuras remontan los muros anteriores o asientan sobre estratigrafía previa, y algunos se adosan a los más antiguos. Estas nuevas estructuras o bien crean nuevas estancias de habitación o bien compartimentan las ya existentes desfigurando la planta previa y generando una malla de espacios rectangulares que ocupa los espacios abiertos de la antigua domus, como es el peristilo y parte del impluvium.

Un estrato B asociado al nivel del siglo III d.C. y que engloba estructuras de adobe, pero también aparecen muros con aparejo de piedra de pequeño tamaño que asientan directamente sobre el nivel de pavimento. La gran mayoría de los muros documentados corresponden a las construcciones altoimperiales que, según las investigaciones tradicionales, se reutilizan tras la destrucción de la ciudad por las incursiones francas (Ramos Fernández, 1983, 154). Los pavimentos documentados en las distintas dependencias son pisos de argamasa de cal con cantos rodados, adobes, arcilla pisada sobre cantos y pequeñas piedras trabadas con

\footnotetext{
5. A continuación haremos un pequeño repaso, más o menos literal, de las descripciones recogidas en las publicaciones de Rafael Ramos Fernández (Ramos Fernández, 1983 y 1991) sobre la estratigrafía documentada en esta casa.
} 
barro. Parece, por tanto, que los muros que presentan un aparejo de piedra pequeña y que asientan sobre los pavimentos deben ser posteriores, mientras que los que tienen un alzado de adobe pueden responder a construcciones previas. En cualquier caso parecen existir al menos dos fases constructivas.

El estrato C correspondiente al nivel altoimperial del siglo I d. C. es al que se atribuye la construcción de las estructuras típicas que definen una casa romana. El estrato engloba paquetes de derrumbe en los que se documentaron materiales cerámicos de construcción, fragmentos de estuco pintado, elementos arquitectónicos y ornamentales esculpidos en piedra y las estructuras ex nоио y los pavimentos propios de una domus altoimperial, es decir, opera tessellata con decoración bícroma vegetal o realizados en blanco y negro, pavimentos de mortero de cal en otras estancias y dos habitaciones con opera sectilia realizados con piezas hexagonales de mármol amarillo, rojo y blanco. Los zócalos de los muros están estucados, conservando pinturas que simulan mármoles, motivos vegetales, animales y candelabros (Ramos Fernández, 1983, 161).

También será en este momento cuando se incorporan el impluvium, el peristilo y algunas fuentes, como elementos arquitectónicos añadidos, ya que el esquema general de las casas sigue siendo el mismo puesto que están cimentadas sobre los restos de los muros republicanos, manteniendo la disposición anterior (Ramos Fernández, 1991, 71). Por tanto, durante esta fase parece que se transforman las construcciones previas en una domus típica altoimperial. Se detecta un patio central con impluvium y peristilo, en torno al cual abren diferentes estancias con mosaicos de opus sectile, tessellatum o signinum. Los muros de aparejo de piedra conservan la pintura mural original con policromía, representando motivos marmóreos, faunísticos $\mathrm{y}$ vegetales.

Por debajo del estrato altoimperial documentan el estrato D, un nivel ibero-romano de la primera mitad del siglo I a. C. hasta la primera mitad del siglo I d. C. Engloba una serie de construcciones y paquetes adscritos a una vivienda de época republicana o iberoromana. Las estructuras serán la génesis de la domus altoimperial, tanto por orientación de los muros como por la pervivencia de la distribución básica de algunas estancias con posterioridad. Los muros de la vivienda de esta fase sirven de cimentación a los de la fase altoimperial (Ramos Fernández, 1983, 164).

Los pavimentos documentados son de diferente naturaleza; un mosaico teselado de tipo helenístico, otro de opus signinum con teselas formando una temática geométrica de rombos, otros constituidos por una solera de cantos rodados cubierta por una capa de cal con la superficie pulida, otros de barro sobre arena, cantos y piedra pequeña, y algunos de adobe.
Los muros de la vivienda de esta fase presentan estucados de cal que en ocasiones tienen una calidad superior a los acabados de la vivienda altoimperial. El mosaico teselado de tipo helenístico aparecido en la estancia suroccidental posee un motivo decorativo complejo. Está encuadrado por un marco de teselas blancas, rojas y negras alternas; en el centro un rosetón; al norte, con teselas azules unas hojas de vid y unos pájaros sobre fondo blanco; a la izquierda una leyenda: $A C O S$; y en el sur otra leyenda en tres líneas: ...L SAILACOS / ...EL SADINICOR / ...SCRAD ... Todo está encuadrado por una banda adornada en los tres ángulos conservados por hojas de vid y en el lado izquierdo por otra hoja flanqueada por sendos pájaros. El mosaico se completa por otra banda conservada parcialmente que reproduce una muralla torreada (Ramos Fernández, 1983, 164-165).

Como ya mencionábamos más arriba, los muros de la vivienda republicana sirvieron de cimentación a las estructuras de la domus altoimperial. En las descripciones de estos muros R. Ramos habla de que se diferencian los de ambas fases por emplear diferentes técnicas constructivas, pero tal y como veremos más adelante, sólo en algunos casos es evidente este cambio de aparejo, ya que normalmente no especifica qué tipo de alzados presentan los muros de ambas viviendas, por lo que es probable que no siempre se realcen los muros republicanos sino que quizá simplemente se reutiliza la misma estructura aún conservada, sin modificar el espacio original o sus muros perimetrales.

Otro dato que nos llama la atención es el hecho de que algunos de los muros de esta fase desaparecen durante los denominados estratos B y C (fase bajoimperial y altoimperial respectivamente) y vuelven a aparecer remontados durante el estrato A (fase visigoda), siguiendo la misma orientación y disposición que los muros construidos siete siglos antes (Fig. 2).

El siguiente estrato es el E, adscrito al nivel iberopúnico o Ibérico II, propio de los siglos III-I a.C. y en él se documentaron muros de mampostería con aparejo irregular y pavimentos de adobe o piedras planas sobre mortero de cal, los cuales aparecían amortizados por las construcciones de la fase republicana (Ramos Fernández, 1983, 165). Los muros están estucados con cal pintada en tonos suaves, predominando el rojo y el azul (Ramos Fernández, 1983, 167).

No contamos con ningún plano detallado de las estructuras halladas, por lo que no sabemos si se llegaron a definir algunos espacios de habitación y de qué forma estos lienzos fueron amortizados por los muros republicanos, quizá realzándolos.

El estrato F se asigna al nivel Ibérico I o Ibérico Antiguo, perteneciente a los siglos III-V a. C. Al igual que ocurría con el estrato E, aquí se habla de la aparición de algunos pavimentos de diferente construcción 


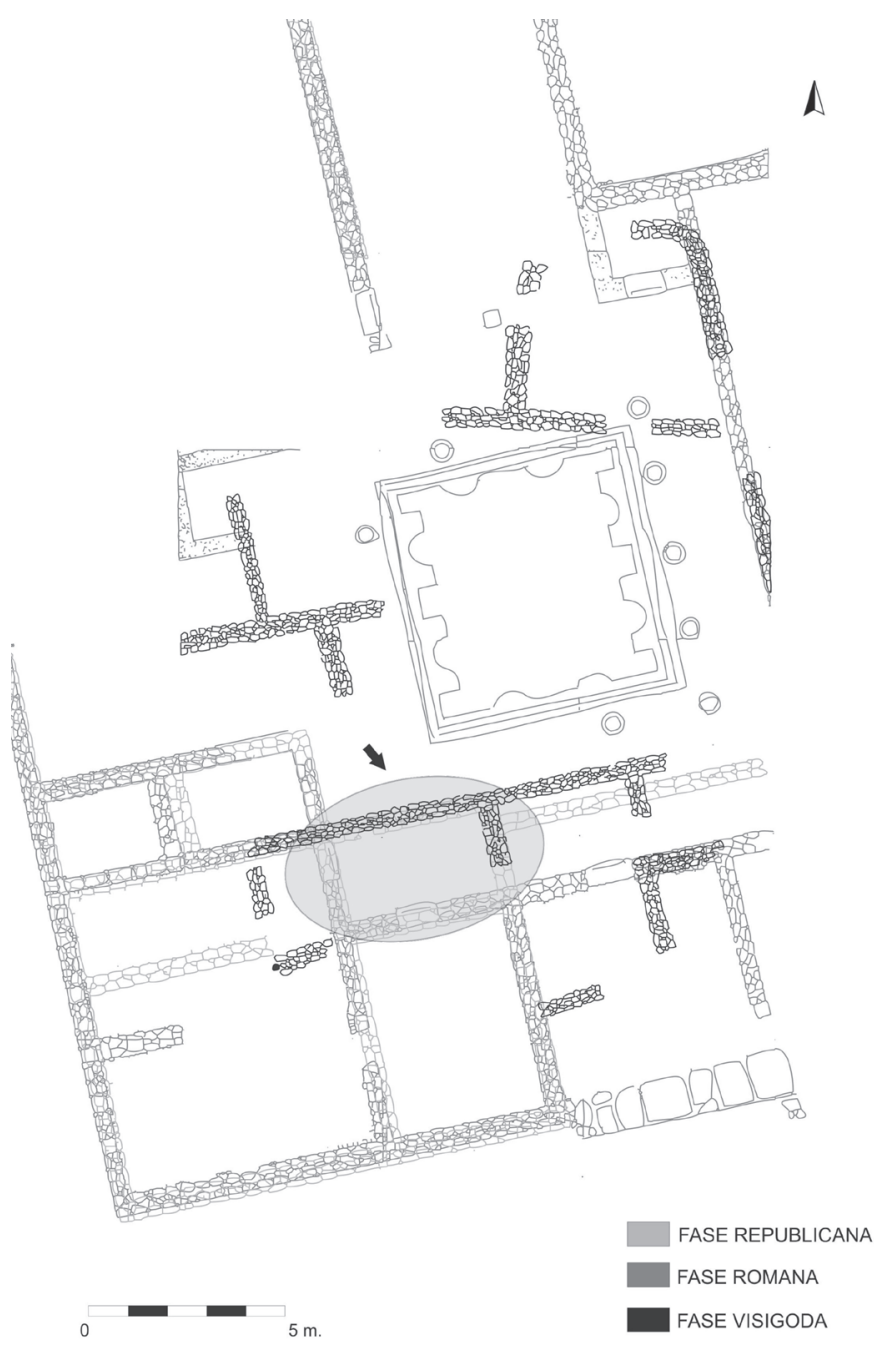

Figura 2: Montaje de los tres momentos constructivos más importantes de la casa, donde se aprecia la incoherencia de algunos de los supuestos realces de lienzos entre unas fases y otras (adaptado de R. Ramos Fernández (1983, 149-151) por L. Abad).

y muros amortizados por la fase posterior pero no especifican si se definen estancias, tampoco hay planos y no sabemos a qué se asocian los pavimentos. Uno de los muros es de gran envergadura (piedras de gran tamaño trabadas con tierra) y proponen que podría ser un tramo defensivo del asentamiento en este periodo (Ramos Fernández, 1983, 171).

Por último se describen los dos estratos más antiguos, el estrato G (Nivel preibérico. s. VII-VI a. C.) y el H (Nivel del Bronce Final), donde se habla de la aparición de pavimentos de tierra apisonada pero sin estructuras evidentes a los que asociarlos (Ramos Fernández, 1983, 172).

\section{LA EVOLUCIÓN ARQUITECTÓNICA DE LA CASA}

Una vez vista la secuencia estratigráfica propuesta tras la excavación de esta vivienda 5-F, así como la inter- pretación de las distintas fases constructivas de la misma desde época ibérica hasta época visigoda, vamos a intentar corroborar o puntualizar todas ellas utilizando otro tipo de indicadores cronológicos, como es la propia arquitectura de la vivienda o los programas decorativos empleados en sus distintos momentos.

El primer problema al que nos enfrentamos es el de la propia disparidad en la representación de las distintas planimetrías publicadas a lo largo de los años, sobre todo las que se refieren a la fase altoimperial de la domus, que es la que se ha consolidado como ruina visitable en el yacimiento (Fig. 3). Presenta una cierta tendencia a la idealización de algunas estancias que en las fuentes romanas aparecen con una morfología canónica, y no refleja del todo la realidad arqueológica documentada en el momento de la excavación. 


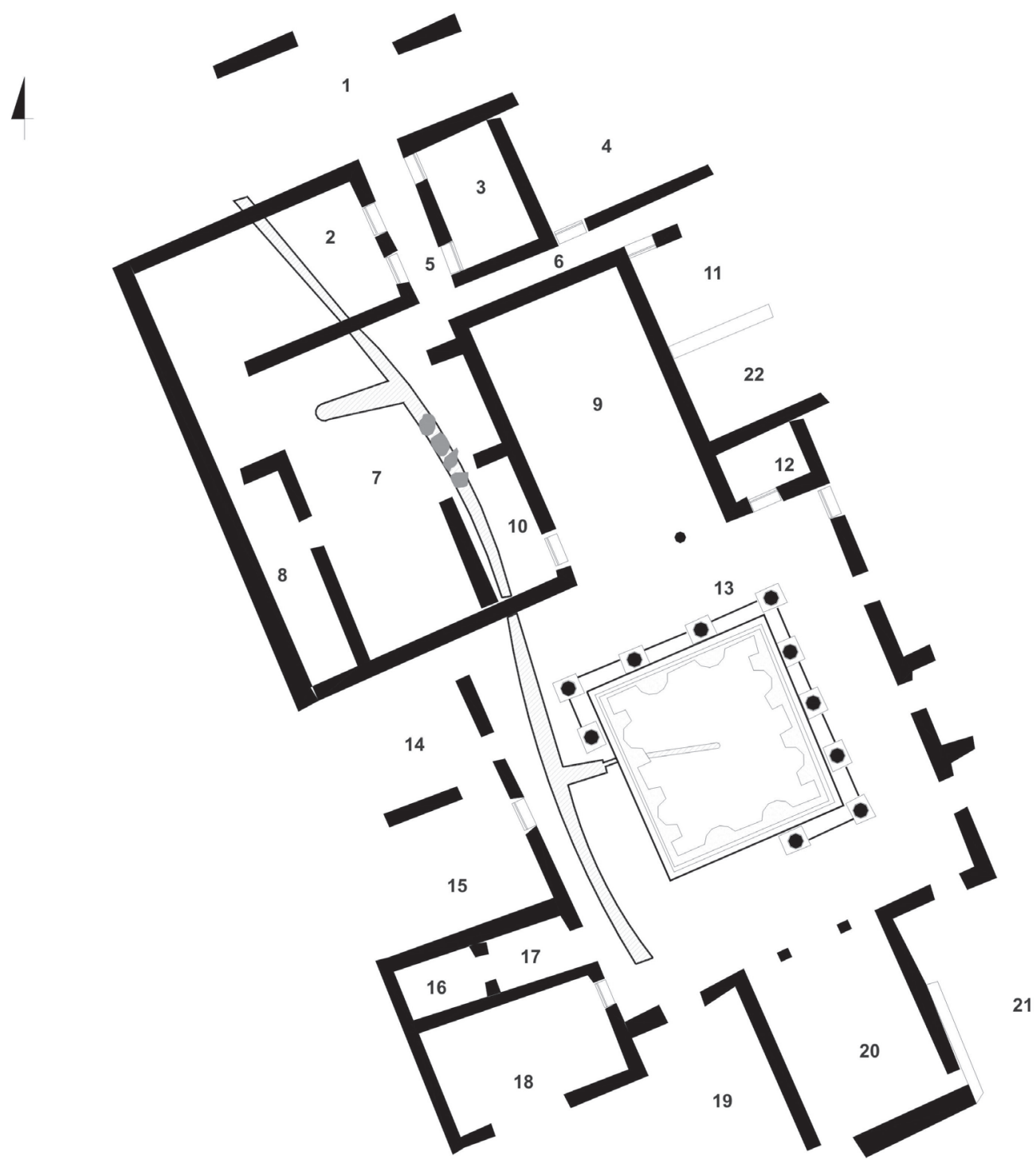

Figura 3: Planta realizada a partir de los restos conservados en el yacimiento en la actualidad. Hemos asignado un número a cada uno de los espacios para facilitar la descripción de cada habitación.

Así podemos ver cómo entre la planta número 1 y la 2 de la figura $4^{6}$ existen algunas diferencias estructurales, marcadas en gris, que afectan sobre todo al sector suroccidental, precisamente a aquellas estancias altoimperiales que según los excavadores fosilizaban otras de una fase anterior, la ibero-romana, y donde apareció el conocidísimo mosaico de tipo helenístico entre los restos de una serie de muros y pavimentos,

6. Existe una tercera versión planimétrica publicada por A. Ramos Molina que se asemeja más a los restos conservados in situ (Ramos Molina, 1997, fig. 8). que configuran al menos tres estancias. Estas reformas altoimperiales alteraron las relaciones físicas y cronológicas entre todos estos pavimentos y las estructuras murarias en teoría asociadas, lo que pudo provocar en parte las diferentes interpretaciones gráficas entre unas publicaciones y otras. Es cierto que pavimentos como este mosaico de tipo helenístico ${ }^{7}$ se pueden fechar en un momento que no iría más allá de finales del siglo II a.C. a mediados del siglo I a.C., tal y como proponen

7. Resulta ser un tipo muy próximo al opus figlinum, realizado con teselas de cerámica (Ramallo, 1990, 137-138). 

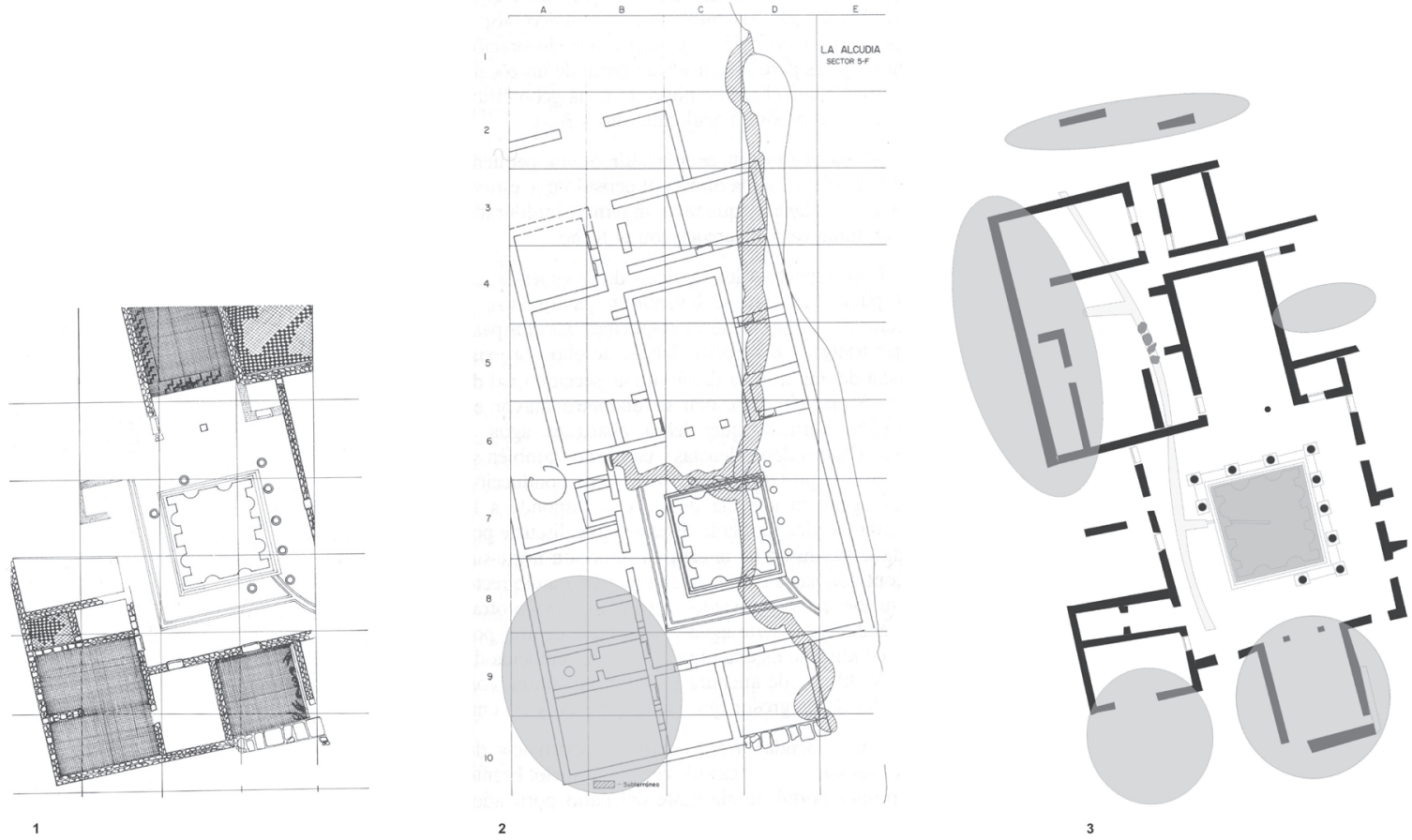

Figura 4: Las plantas 1 y 2 fueron publicadas por R. Ramos (1983, fig. 2, 150 y 1991, fig. 5, 75 respectivamente) y la 3 fue realizada por nosotros en base a los restos conservados en el sitio, los cuales han sufrido numerosas restauraciones a lo largo de los años.

algunos autores en base a su iconografía y a los epígrafes con caracteres latinos de nombres ibéricos que se representan en él (Ramos Folqués, 1975, 81; Tammisto 1997, 114 y 124; Gómez Pallarés,1997, 39; Corell, 1999, 79; Abad,1986-1987, 102-103; Fernández Díaz, A. 2003 y 2004; Lara, 2007, 162) , pero la adscripción a estos contextos de otro tipo de estructuras, como los propios lienzos, no resulta tan clara. No obstante, existen algunos muros que se atribuyen a las estancias ibero-romanas gracias al propio aparejo de los mismos; se describen éstos como lienzos realizados «con piedra seca o cogida con barro ocasionalmente con la técnica de «telar» de posible origen africano, aunque también emplearon adobes» (Ramos Fernández, 1991, 71); algo que a pesar de las continuas restauraciones sufridas por las ruinas de esta domus todavía puede ser apreciado en alguno de los lienzos conservados, lo que facilita en gran medida la identificación entre las estructuras originales y las recrecidas más tarde.

8. En la mayoría de estas obras existen descripciones pormenorizadas tanto de la iconografía como de la epigrafía y de las técnicas empleadas en la construcción de este mosaico, de ahí que no nos detengamos de forma exhaustiva en estos aspectos del pavimento.
Éste es el caso del muro de cierre norte de la habitación pavimentada en origen con el mosaico helenístico (habitación 18), que más tarde se reemplearía colocando una repavimentación de opus signinum perdida en la actualidad. En su alzado meridional (Fig. 5) podemos observar un evidente cambio de aparejo a una cota que coincide con el nivel de uso y construcción de estancias que todavía conservan la pavimentación original de la fase altoimperial (habitaciones 15, 16 y 17), diferenciándose un primer tramo que se correspondería en mayor o menor medida con las descripciones sobre las técnicas murarias republicanas del yacimiento mencionadas más arriba -piedras de pequeño tamaño colocadas de forma irregular y trabadas con barro- y un segundo alzado del que se conservan apenas dos hileras de sillares escuadrados en lo que podrían ser los restos de un opus quadratum, técnica muy frecuente desde el cambio de era y que a partir de finales del siglo I d.C. en adelante dejará de ser tan generalizada en la construcción, debido sobre todo al perfeccionamiento de la técnica latericia y los revestimientos marmóreos (Lugli, 1968, 331); un hecho que podría estar indicando una fecha constructiva de estos realces en torno a época flavia, tal y como se ha propuesto en otros contextos constructivos de la ciudad que muestran un evidente 
0

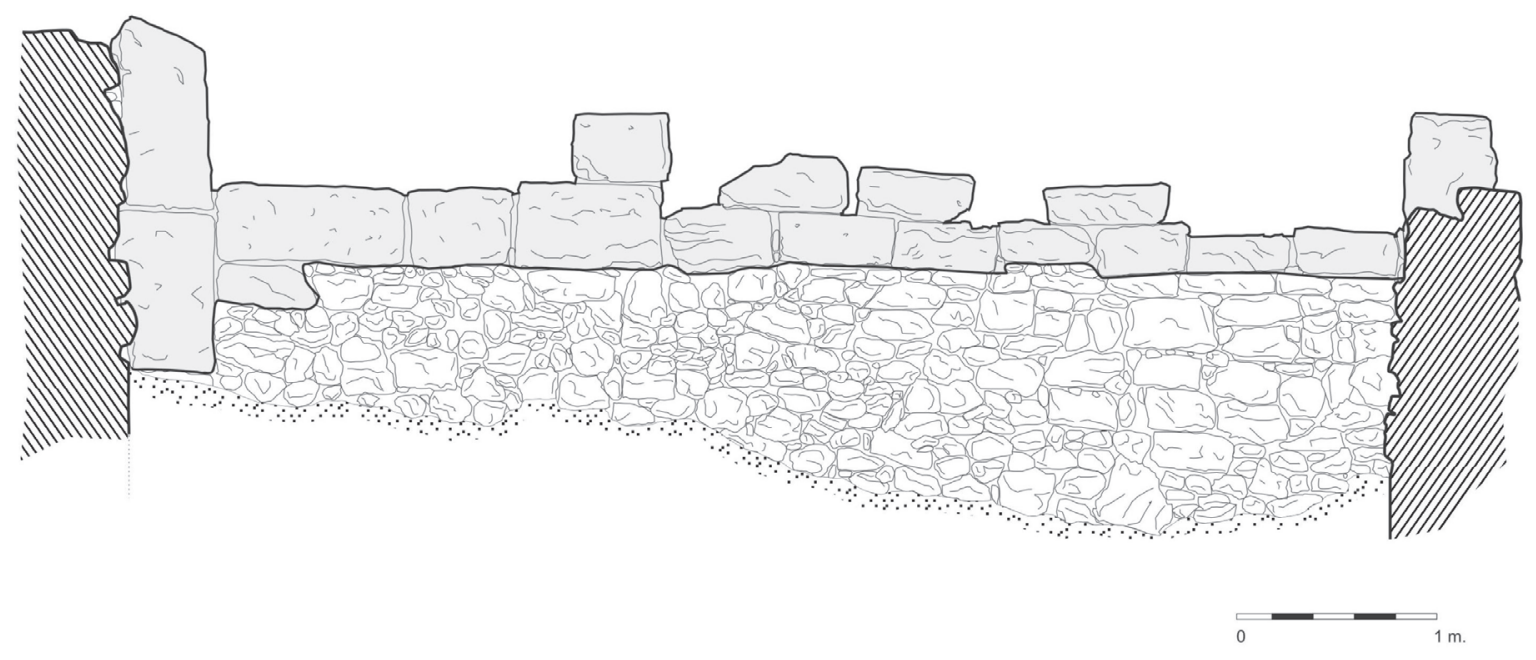

Figura 5: Alzado meridional del muro de cierre norte de la habitación 18. En él se pueden apreciar la diferentes técnicas empeladas para su construcción, lo que podría ser un indicativo de dos fases edilicias.

desarrollo arquitectónico para estos momentos (Abad, Moratalla y Tendero, 2000).

Para este momento inicial de la casa de supuesta cronología ibero-romana, también se documentaron otras estancias. Una ubicada al norte de la habitación con el mosaico helenístico, en la que se encontró un pavimento de opus signinum con teselas en blanco que formaban un diseño de retícula (Ramos Folqués, 1975, 70; Ramos Fernández, 1975, 145, lám. LXXII, fig. 5; Abad, 1989, 161-162; Lara, 2007, 155), y a continuación de ésta, algo más al norte, otra estancia dotada de un pavimento de adobes revestidos de cal y con muros de mampostería enlucidos también con cal y pintados de rojo (Ramos Fernández, 1989, 236-237). En esta última estancia podemos encontrar algunos problemas de adscripción entre el pavimento de adobes y los muros a los que se asocia; si bien es cierto que la técnica empleada en dicho pavimento se puede asociar a contextos arquitectónicos propios del mundo ibérico algo romanizado, no resulta tan evidente en el caso de la pintura mural roja aparecida en las paredes a las que se atribuye este suelo, ya que como bien es sabido en época ibérica el concepto pictórico en los ambientes domésticos es meramente funcional, se encalan las casas para aislarlas de la humedad no por decorarlas (Fernández, 2004, 170). De este modo la pintura mural se convierte en un magnífico indicador de la romanización de una zona y aunque parece que en la génesis de esta casa hay un marcado gusto del propietario por incluir elementos clásicos en su nuevo hogar, como los pavimentos de signinum con teselas, resulta más difícil atribuir a este momento la decoración pictórica de esta estancia; en época altoimperial esta habitación sí aparece claramente decorada con un panel mural tripartito, compuesto por un zócalo en rojo sobre el que se pinta una banda en verde y un desarrollo vegetal con arbustos, rosas y capullos, por lo que no sería extraño pensar que en realidad esos restos de pintura roja atribuidos al primer momento de la casa se realizaron en realidad en la segunda fase constructiva de la misma, cuando aparecen de forma clara los elementos de un ambiente plenamente romanizado; sobre todo si tenemos presente dos cosas; por un lado la no identificación de niveles de uso y construcción claros en el momento de su excavación ${ }^{9}$ y por otro que resulta muy curioso que en el resto de habitaciones no se hallaran evidencias de pintura mural, sobre todo en la estancia del mosaico helenístico que, como ya hemos visto, resulta ser un elemento de prestigio en un momento y lugar donde este tipo de ornamentos son todavía incipientes, confiriéndole a este espacio un carácter representativo ${ }^{10}$.

9. Hemos de recordar que la estratigrafía documentada es bastante difusa, ya que en un mismo estrato se incluyen todos los procesos sufridos por la casa en una fase histórica concreta, desde su construcción hasta su reforma o destrucción en la siguiente fase o estrato, lo que dificulta mucho el establecimiento de las relaciones físicas entre las estructuras.

10. Lorenzo Abad (Abad, 2004, 76) la interpretó como un tablinum, es decir, el lugar que haría las veces de despacho del propietario, aunque otros autores han sido algo más atrevidos y han propuesto una funcionalidad más simbólica para el mismo, definiéndola como un oikos, una estructura no 


\section{1. LA DOMUS ALTOIMPERIAL}

\section{1. 1. Las técnicas constructivas}

Una vez visto el tipo de arquitectura que definía la primera fase claramente doméstica de este sector ${ }^{11}$, vamos a intentar analizar tanto las técnicas constructivas como los programas ornamentales empleados en las distintas estancias documentadas para la fase plenamente romana de esta domus, y así afinar algo más la interpretación funcional de las mismas y su posible evolución cronológica.

La primera cuestión en la que nos debemos detener vuelve a ser la de la disparidad en las planimetrías existentes de la excavación con la realidad arqueológica fosilizada en el sitio en la actualidad, tal y como podemos ver en la figura 4 . En este sentido destaca de manera evidente la habitación 20 , en la que en origen aparecía un muro de cierre septentrional que comunicaba dicha estancia con el patio porticado o peristilo y que probablemente se desmontó en un intento de enfatizar el canónico eje axial entre triclinium, patio (atrio o peristilo) y tablinum recogido en las fuentes clásicas, cuya interpretación funcional fue atribuida por sus excavadores a las habitaciones 9,13 y 20 respectivamente. De esta forma, el tablinum de la casa itálica tradicional es ante todo el despacho del dueño, donde el propietario se retira para estar tranquilo a salvo de la agitación cotidiana, o donde trata sus asuntos o recibe a sus amigos, por lo que cabe decir que es una habitación dedicada a actividades culturales, de ahí que cobre importancia la ubicación cercana de este tipo de espacios a las zonas de la casa en las que también se recibiría a los invitados del dominus, como los comedores o patios (Carandini, 1989, 109; Thébert, 1987, 363). A pesar del evidente desmonte de este lienzo en el momento de la restauración del edificio a favor de la creación de un acceso monumental en teoría más propio de estancias de representación, a nuestro parecer, independientemente de que la habitación tuviera una entrada más o menos compleja desde el peristilo, la funcionalidad atribuida a la misma como despacho del dominus no deja de ser la más factible, puesto que como veremos a continuación, este es uno de los pocos espacios pavimentados con mosaicos teselados, lo que

oficial de tipo asociativo similar a las detectadas en Grecia (Ferreruela et alii, 2003, 225-226) y que vendría a explicar la aparición de ese pavimento de tipo helenístico con distintos nombres de «socios» (Lara, 2007, 164).

11. Recordamos que anteriores a la fase ibero-romana se documentaron una serie de muros de cronología previa (siglos III-I a.C.) que no llegaban a definir estancias claras y que aparecían amortizados o remontados en parte por las estructuras republicanas que hemos descrito. nos podría estar indicando la importancia dada a este ambiente.

Una vez aclarada esta cuestión gráfica, vamos a detenernos un momento en los tipos de aparejos empleados en la construcción de los muros perimetrales de esta casa altoimperial en parte cimentada sobre la republicana. En este sentido, en una primera observación in situ detectamos algunos indicios de restos de pintura mural asociados a los propios muros, lo que nos ayudó a interpretar como originales dichos lienzos, al menos en su parte más baja. De esta forma, hemos seleccionado algunos ejemplares murarios en los que sí parece haber restos conservados del alzado original y que por tanto presentan cierta fiabilidad a la hora de analizar las técnicas arquitectónicas empleadas en su construcción (Fig. 6).

Entre ellos contamos con algún ejemplar realizado en un opus quadratum no del todo canónico (Fig. 6.4), que podría asimilarse más bien a una estructura mixta en damero (Adam, 2008, 129), ya que a pesar de conservarse una única hilada, se observa una disposición de sillares escuadrados alternados con piedras de menor tamaño. La característica principal de este tipo de aparejo es que los bloques más grandes reposan unos sobre otros dando la sensación de tablero, mientras que los huecos dejados por éstos se rellenan de piedras más pequeñas (Fig. 7).

Otro dato a destacar es la aparición de un único lienzo realizado en opus africanum (Fig. 6.6), cuyo desarrollo comienza a una cota determinada del muro -marcada con una línea negra en el dibujo- y que podría estar indicando una fase de realce del muro original, realizado en opus vittatum, en época altoimperial, cuando la casa es ampliada. La técnica africana, llamada así por tener su origen en las regiones cartaginesas del norte de África, será adoptada y desarrollada con algunas variantes por los romanos desde su ocupación en esta zona, apareciendo ejemplos también en otros lugares del imperio, sobre todo en la parte meridional de Italia e Hispania (Adam, 2008, 131). Existen algunas evidencias ya en época medio y tardorrepublicacna en la Península, como es el caso del Grau Vell de Sagunto. Consiste en una disposición de bloques de grandes dimensiones, puestos en horizontal y vertical formando cadenas verticales.

La última de las técnicas documentadas en los muros de esta domus es el opus vittatum, que resulta ser la más empleada en dicha edificación (Fig. 6.1-3, 5). Se trata de una obra compuesta por piedras de perfil cuadrangular dispuestas horizontalmente formando un aparejo isódomo o pseudo-isódomo de pequeñas dimensiones. Este tipo de técnica fue utilizada de forma sistemática en Roma desde época augustea hasta mediados del siglo II d. C., desapareciendo prácticamente hasta su reempleo en el siglo IV. Sin embargo, en His- 
ALZADO NORTE DEL MURO DE CIERRE MERIDIONAL HABTACIÓN 11
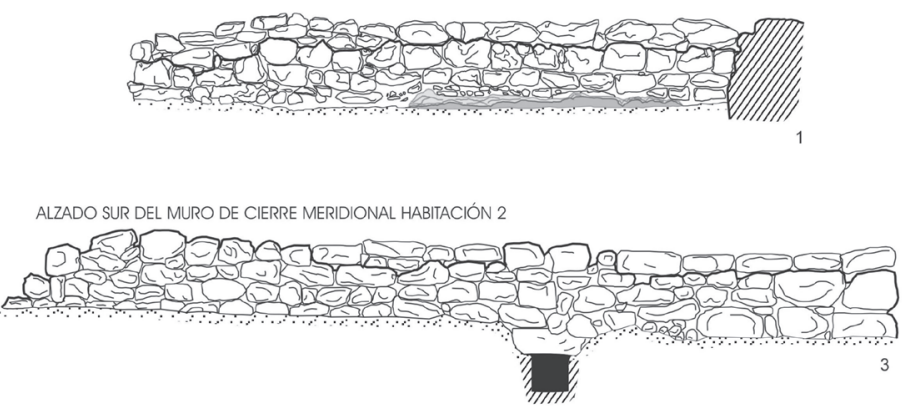

ATADO ESTE DEL MURO DE CIERRE ORIENTAL HABTACIÓN 9

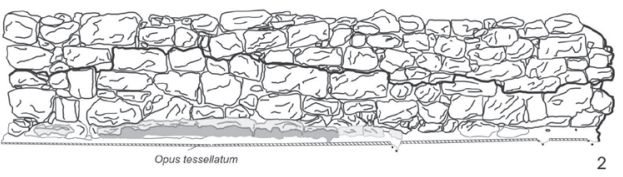

ALZADO NORTE DEL MURO DE CIERRE MERIDIONAL HABIIACIÓN 20

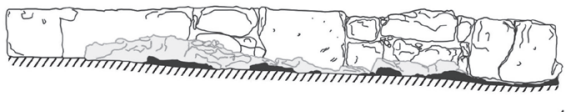

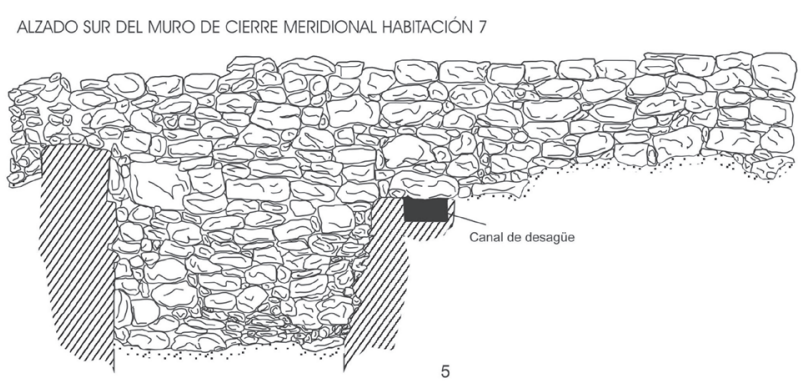

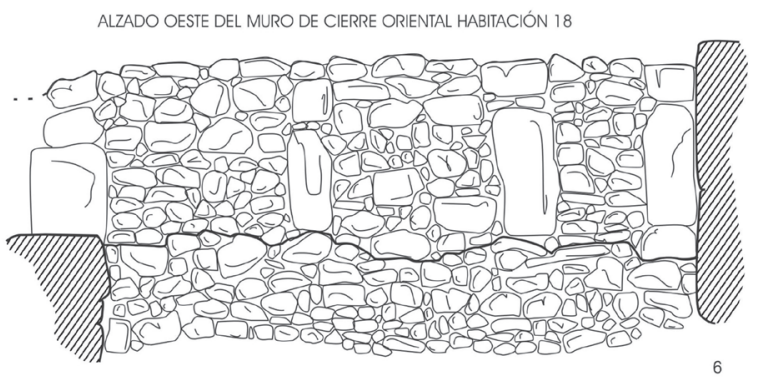

Figura 6: Alzados de la domus 5-F con los distintos aparejos empleados en su edificación.

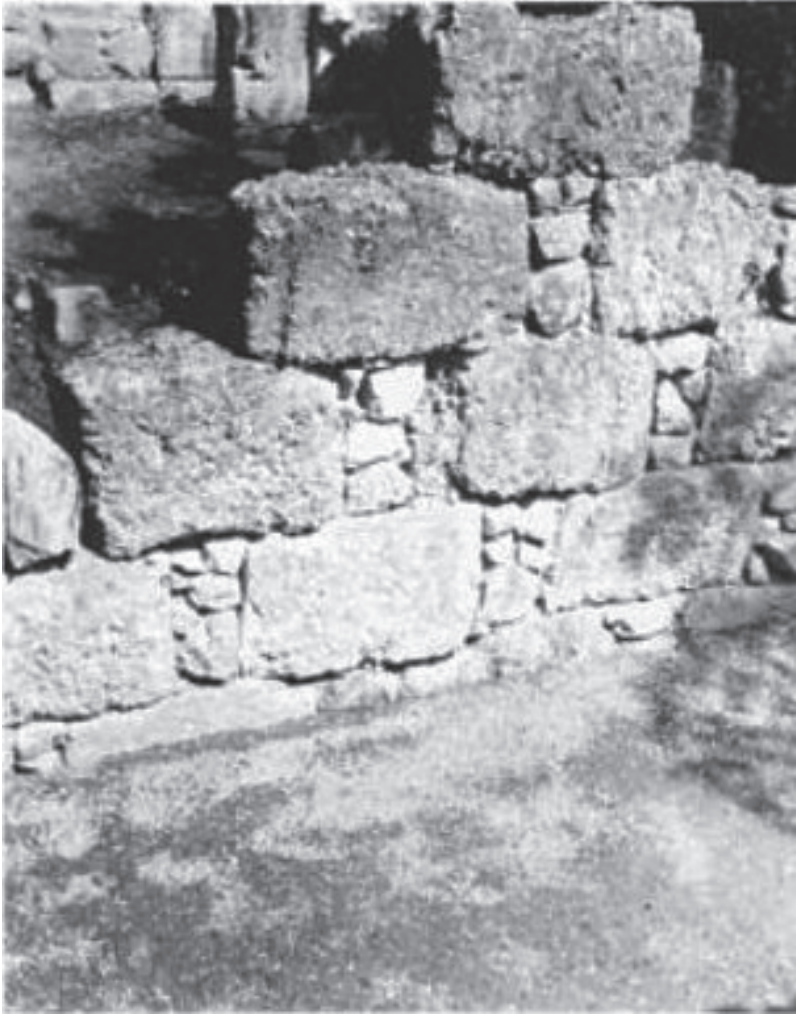

Figura 7: Vista de un aparejo mixto en damero procedente de «la domus con atrium» de Bolsena (Italia) (Adam, 2008, 129, fig. 275). pania parece que a pesar de ser una técnica bastante usada, no alcanzará el gran auge dado en otras regiones del Imperio como la Galia o Italia (Adam, 2008, 148).

Por tanto, el reiterado empleo de este tipo de obra en la construcción de los ambientes domésticos de La Alcudia, podría aportar nuevos datos arqueológicos que corroboren los históricos, y en concreto una segunda deductio de veteranos de origen itálico en la colonia en época de Augusto, cuando ésta recibe el calificativo de Augusta (Alföldy, 2003, 38); este hecho podría reflejarse no sólo en los restos numismáticos o epigráficos documentados en el yacimiento ${ }^{12}$, sino también en la arquitectura, que en este caso sería realizada por una población con altos contingentes itálicos, con unos gustos y conocimientos artesanos determinados, en un momento en que técnicas como el opus vittatum tienen un gran apogeo en la arquitectura doméstica de la Urbs.

12. La fundación de Ilici como colonia a partir de la deductio de veteranos está probada no sólo por la aparición de símbolos legionarios en las monedas de Augusto y Tiberio sino por la aparición de una placa de bronce con un catastro en el que se atestigua el reparto de fundos a 10 ciudadanos romanos procedentes de varias ciudades y regiones de Italia e Hispania (Alföldy, 2003, 43). 


\section{1. 2. La infraestructura hidráulica}

En el ámbito estructural de la casa altoimperial, además de los muros perimetrales que definen cada una de las estancias de la misma, destaca también la propia infraestructura hidráulica de la vivienda. Nos referimos sobre todo al impluvium o estanque del peristilo, al canal de desagüe del patio, que atraviesa la casa por debajo del nivel de uso, y a la galería sanitaria subterránea abierta bajo la habitación 14.

Uno de los principales elementos indicadores de la plena romanización en los ambientes domésticos son los llamados patios porticados o peristilos, los cuales se convirtieron en el auténtico corazón de la parte pública de la vivienda, donde se acogía al visitante; de ahí que en ellos a menudo se ubicaran jardines, fuentes o estanques y que la mayor parte de las salas de recepción se encontraran situadas a su alrededor (Thébert, 1987, 347). En el caso que nos ocupa, el peristilo está formado por un estanque polilobulado de unos $49 \mathrm{~m}^{2}$, revestido de mortero hidráulico u opus signinum, y rodeado de columnas de las que se conservan algunas basas áticas ${ }^{13}$ in situ, en cuyos laterales aparecen unos rieles de sección cuadrangular que nos indican la posible existencia de celosías caladas, quizá de madera, entre las columnas, en lo que sería una especie de balaustrada alrededor del estanque (Fig. 8).

El mantenimiento de este tipo de embalses, así como las acometidas de agua de la red doméstica, se realizaban normalmente mediante tuberías cerámicas o en ocasiones, como en el caso de las aparecidas en la habitación 16, de plomo. Sin embargo, cuando se necesitaba la circulación de un mayor caudal de agua, se optaba por construir conductos o canales rectangulares muy superficiales, tapados únicamente con losas a la altura del pavimento (Fernández Casado, 1983, 73). Éste es el caso de la domus 5-F, donde aparece un canal de desagüe y abastecimiento de agua de unos 30 $\times 25 \mathrm{~cm}$, construido en opus caementicium y revestido de cal, que atraviesa la casa de norte a sur cruzando por el peristilo, punto en el que aparece un ramal que comunica con el interior del estanque polilobulado, lo que atestigua su función de drenaje de agua desde dicha estructura.

En lo que se refiere al alcantarillado de la red urbana de Ilici, se han documentado tramos del mismo al sur del sector 7-F, constituidos por un conducto subterráneo de $1,30 \mathrm{~m}$ de alto por $0,60 \mathrm{~m}$ de ancho, hecho con mortero de cal y barro, con bóveda de medio punto

13. Estas basas muestran toros bastantes simétricos y un plinto poco pronunciado, por lo que podrían situarse en la primera mitad del siglo I d. C., aunque es difícil establecer una cronología precisa por la simplicidad de las molduras (Escrivà, 2005, A143, 100)

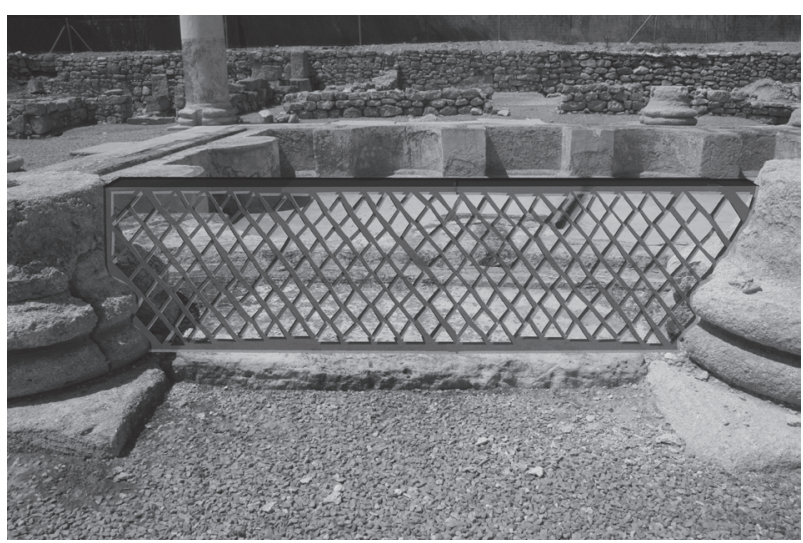

Figura 8: Imagen de dos de las basas conservadas con restitución de lo que sería la celosía encastrada entre ambas.

que en un determinado momento se convierte en bóveda plana (Ramos Fernández, 1975, 226-227 y 1991, 72). No conocemos el trazado exacto del alcantarillado en su totalidad, pero la red solía ir por debajo de los grandes ejes viarios de la ciudad (cardo y decumano) y los últimos ramales iban en galerías subterráneas con accesibilidad y con bóveda propia -como los tramos documentados en el sector 7-F- dentro de la cual podían ir los conductos a modo de tubería o en canal libre. Existen numerosos ejemplos de este tipo de galería o cloaca bajo las redes viarias de ciudades romanas como Emerita Augusta, Italica o Asturica Augusta entre otras. En esta última la red de saneamiento estaba formada por galerías adinteladas que serán sustituidas a finales del siglo I d. C. por otras más grandes con bóvedas de cañón (Luengo, 1955).

La galería documentada por debajo de la domus 5-F fue excavada en el terreno, revestida de barro y su cubierta era abovedada. Probablemente es una prolongación del tramo aparecido en 7-F y sus excavadores no supieron qué interpretación darle, ya que el hecho de que estuviera desprovista de un revestimiento hidráulico que la impermeabilizara no les hizo plantearse la posibilidad de que se tratara de una cloaca o galería sanitaria, pero sabemos que la construcción de este tipo de galerías suele ser diferente a la de los canales de aguas blancas ya que los suelos se suelen pavimentar con losas de piedra o ladrillos y las paredes no suelen tener revestimientos de opus signinum porque no es necesario impermeabilizar la estructura para evitar la pérdida de aguas residuales. En el subterráneo aparecido debajo de la casa, a la altura del estanque del peristilo, se encontraron dos cámaras superpuestas comunicadas por una estrecha boca tapada con un ladrillo, que con toda probabilidad hicieron las veces de arquetas de bifurcación o de rotura de presión, técnica frecuente para evitar el estancamiento en los nudos importantes.

Normalmente los conductos de aducción desde las casas particulares se hacían o bien por tuberías cerá- 
micas o por canales rectangulares que desaguaban en los colectores subterráneos de las calles o aceras (Fernández Casado, 1983, 77) pero en este caso, pensamos que la propia disposición de la casa, cercana a la orilla del río, donde se encontró la boca de desagüe, propició la construcción de un ramal de la cloaca siguiendo el trazado y la orientación de la casa, abriendo incluso una de las bocas de acceso a la galería ${ }^{14}$ desde una estancia que se ha interpretado como la zona de cocinas (habitación 14) y que es donde ésta alcanza la máxima pendiente (Fig. 9), de ahí que se construyeran aquí las dos cámaras para la rotura de la presión ${ }^{15}$. Es probable que los investigadores que efectuaron la excavación no interpretaran esta galería como una cloaca precisamente por ese motivo, por tener un acceso tan claro desde la casa, por lo que pensaron en la posibilidad de que fuera «una galería que al estar en el subsuelo de una vivienda necesariamente se realizó como sitio de ocultación, por algún tipo de miedo histórico» que no saben explicar (Ramos Fernández, 1991, 77).

En cuanto a la cronología de este conducto, la ausencia de materiales en las labores de excavación del mismo, excepto un candil islámico y un ladrillo romano, dificulta el establecimiento de la construcción inicial de la estructura y su pervivencia a lo largo del tiempo, aunque se le asignó una fecha entre el siglo II y el VI d.C. (Ramos Fernández, 1991, 77), quizá extraída de los diferentes momentos constructivos documentados en la casa que como sabemos no van más allá de época visigoda. No obstante, el hecho de que se construya debajo de esta edificación nos lleva a pensar que llevar su construcción al siglo II d. C. es improbable, ya que el gran desarrollo arquitectónico de la vivienda se realizó a mediados del siglo I d. C., momento que nos da una fecha ante quem para la realización de esta galería construida por debajo de la solera de la casa.

\section{1. 3. Los programas decorativos}

En el estudio de una típica vivienda romana, el análisis de sus programas decorativos quizá sea uno de los indicadores cronológicos más interesantes, ya que en un mundo tan estandarizado como el romano, el empleo de un material ornamental o de una iconografía decorativa determinada nos permite definir tanto el grado de asimilación de las modas del Imperio como el nivel socioeconómico del dominus.

14. Normalmente estas galerías tenían que poseer accesos que permitieran la circulación de personas para facilitar las labores de limpieza periódica.

15. En Calagurris Iulia (Calahorra) existe un tramo de cloaca, la número 1 de la calle San Andrés, en el que la pendiente pasa de $7.19 \%$ en un tramo de $12 \mathrm{~m}$ al $3.84 \%$ en un tramo de $18,77 \mathrm{~m}$ (Andrés et alii, 2002, 65).
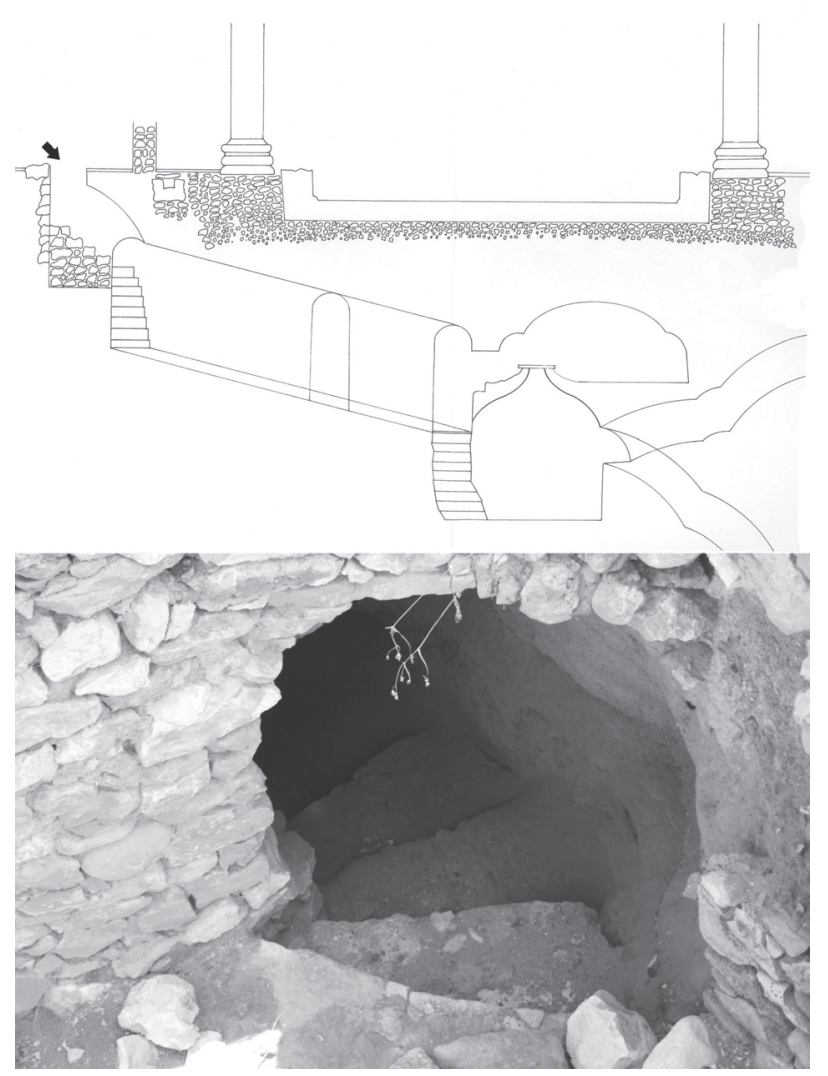

Figura 9: Vista del acceso abierto a la galería subterránea desde la estancia 14 de la domus y sección transversal de la misma publicada por A. Ramos Molina (1997, fig. 9).

Estos programas decorativos engloban tanto el gusto por pavimentar los suelos de la casa con un determinado material, más o menos suntuoso, como el hecho de decorar con un mayor o menor grado de detalle las paredes de determinadas habitaciones.

En el caso de los suelos (Fig. 10), en esta domus destacan sobre todo tres técnicas, una más funcional y menos ornamental consistente en pavimentos de mortero de cal o mortero hidráulico (revestimiento del estanque del peristilo), que nos podría estar indicando una funcionalidad más práctica de los espacios en los que se utiliza esta técnica, algunos de los cuales son zonas de paso. Y otras dos técnicas claramente decorativas, aparecidas en aquellas habitaciones con un marcado carácter representativo o privado. Nos referimos sin duda al opus tessellatum y al opus sectile ${ }^{16}$.

16. Recordamos que existen algunas diferencias entre la planta de la figura 10 y la publicada por R. Ramos Fernández sobre la excavación de este sector (Ramos Fernández, 1983, fig. 2). No obstante, utilizaremos esta por ser la única en la que se representan todas las estancias exhumadas, lo que facilita la ubicación de los hallazgos ornamentales que describimos. 

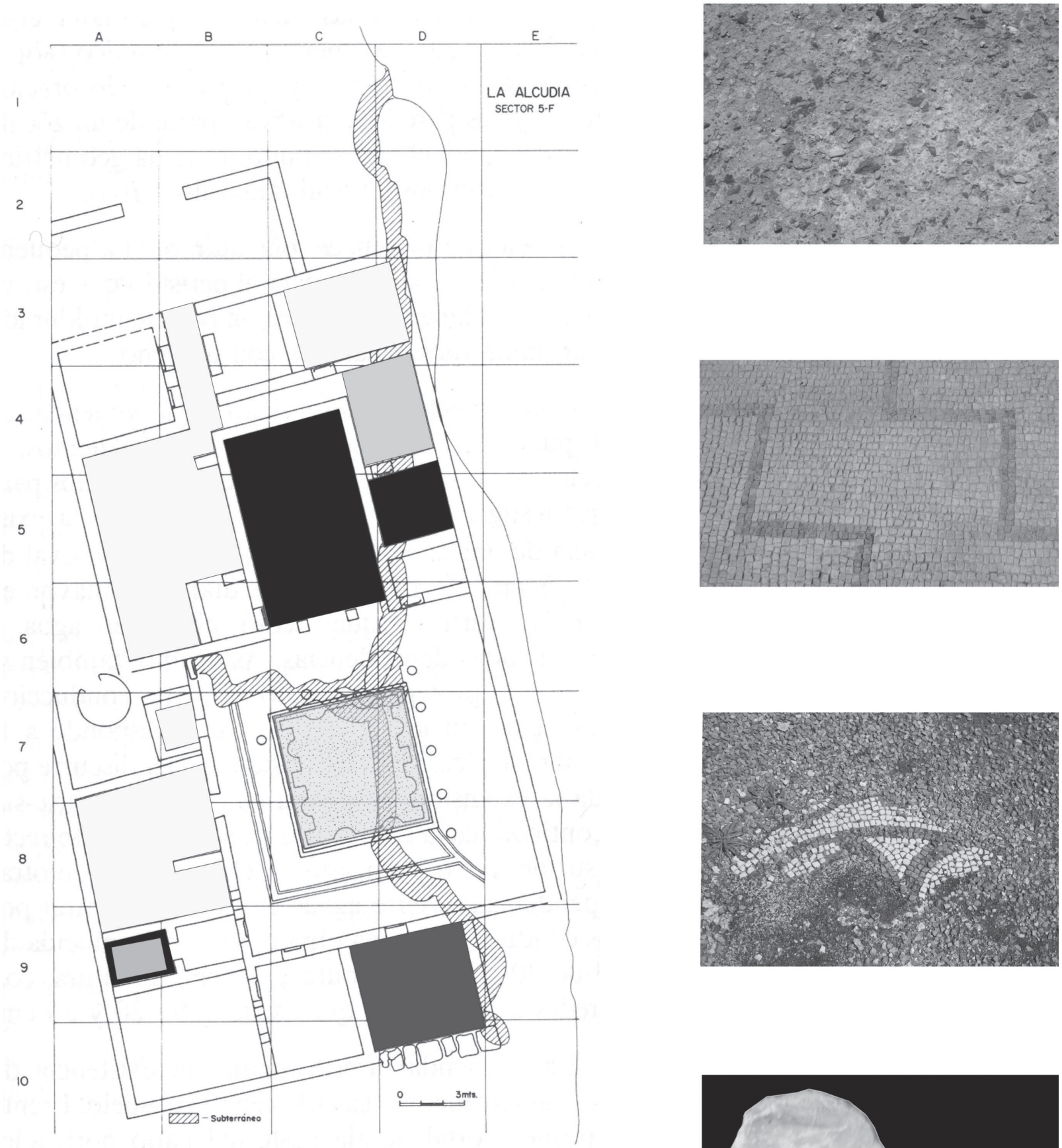

Pavimento de opus sectile

Pavimento de opus tessellatum en blanco y negro.

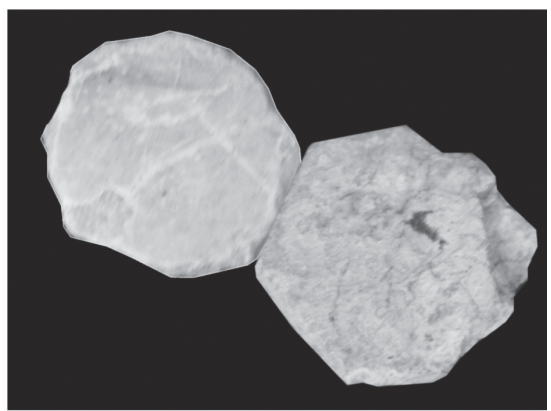

Pavimento de opus signinum

Pavimento de opus tessellatum polícromo.

Figura 10: Planta con la localización de los diferentes tipos de pavimentos aparecidos en la vivienda. 
Entre los mosaicos teselados de la casa, aparecen dos variantes, las alfombras musivas en blanco y negro y las polícromas. De las primeras contamos con dos ejemplares hallados in situ en el momento de la excavación, el de la habitación 9 y el de la 22, en los que el desarrollo del pavimento conservado presenta un fondo blanco rodeado de una orla de enmarque geométrica de teselas negras formando una cadena de ángulo recto. El estado de conservación de estos mosaicos en el momento de su hallazgo no nos permite atestiguar si hubo algún tipo de decoración central o contaron con un único suelo en blanco, así como si hubo algún tipo de policromía. No obstante, la falta de teselas polícromas en los niveles de colmatación de la casa nos puede estar indicando que se trataba de pavimentos en blanco y negro que, a pesar de su simplicidad compositiva, podrían situarse en un ámbito cronológico alrededor de los siglos I y II d. C., cuando las producciones musivas en blanco y negro serán frecuentes en el litoral levantino ${ }^{17}$, con representaciones muy locales de motivos muy difundidos en Italia, de ahí la simplicidad de los esquemas compositivos de estos ejemplares de Ilici (Fernández Díaz, 2004, 169).

En ese mismo ámbito cronológico podría incluirse el mosaico polícromo aparecido en la habitación 20, del que únicamente se conservan algunos motivos vegetales en rojo y negro sobre un fondo blanco. Mosaicos de este tipo aparecen en otros ambientes domésticos de La Alcudia, como el hallado en una domus del siglo II de las afueras del yacimiento, aunque este ejemplar presentaba una composición figurada (Ramos Fernández, 1983; Ramallo, 1990, 147; Fernández Díaz, 2004, 169) mucho más elaborada que el mosaico de 5-F.

Por último, aparecieron dos suelos realizados en opus sectile, uno en la habitación 11 y otro en la 16. Ambos emplearon placas de mármol de módulo pequeño, el primero de forma hexagonal y el segundo de formas rectangulares y triangulares.

Los soportes pétreos utilizados en estos pavimentos son descritos como mármoles de color rojo y blanco, pero no se especifica qué tipo de marmora son. No obstante, gracias a los ejemplares de placas hexagonales conservadas en el museo de La Alcudia y que con toda probabilidad pertenecieron al pavimento aparecido en la habitación 11, podemos apuntar que las placas descritas como mármol de color rojo en realidad son piezas realizadas en la variante rosada de Buixcarró, una caliza procedente de Játiva, cuya explotación se constata al menos desde el cambio de era en ciudades como Saguntum y Saetabis, aunque su uso más gene-

17. Encontramos la misma combinación de sencillos mosaicos en blanco y negro con otros de policromía limitada, en la villa de la Quintilla (Lorca) (Ramallo, 1995). ralizado se dará en la horquilla cronológica que oscila entre finales del siglo I y comienzos del siglo II d.C. (Rodá, 1997, 49). En La Alcudia se ha constatado el empleo de este tipo marmóreo en otras construcciones de carácter público, como es el caso de un pavimento de opus signinum con crustae de buixcarró localizado sobre el muro perimetral de las conocidas como termas occidentales (Muñoz y Sarabia, 2000), cuya construcción se sitúa alrededor de mediados del siglo I d.C. (Abad, Moratalla y Tendero, 2000).

Estos opera sectilia de pequeño módulo son composiciones pavimentales obtenidas por repetición de lastras simples o unidades modulares compuestas, cuyas dimensiones no pasan del pie romano (unos 30 $\mathrm{cm})$. Estos pavimentos no suelen estar condicionados por la prefabricación de las baldosas; las placas se tallan a pie de obra y se colocan directamente sobre la cama de mortero (Guidobaldi, 1985, 208). Los ámbitos privados de Hispania en los que aparece este tipo de módulo suelen presentar combinaciones que son normalmente de una gran sencillez y claramente paralelizables con el repertorio itálico del siglo I d. C. Los suelos de mármol se localizan en las estancias principales de las viviendas, por lo general oeci o triclinia, y no aparecen de forma exclusiva en las casas más lujosas, ya que no tenían que cubrir por completo el suelo; puede haber pequeños emblemata centrales sobre cama de signinum encargados para edificaciones más modestas (Pérez, 1996, 44). Éste podría ser el caso de la domus estudiada aquí, ya que uno de los dos conservados parece corresponder a un emblema central, puesto que según las descripciones de los excavadores apareció rodeado de un mosaico teselado blanco con filete lateral en negro (habitación 16) ${ }^{18}$.

La sencillez compositiva de los diseños mencionada anteriormente, así como la concordancia y homogeneidad de los materiales marmóreos empleados, no responde tanto al carácter más o menos suntuoso que se le quiera dar a la casa como a la época a la que se podrían adscribir estos suelos. Sabemos que con el desarrollo del fenómeno de la marmorización, a partir de época de Augusto, la explotación de canteras y el comercio del mármol como soporte constructivo de prestigio será cada vez más importante, lo que posibilitaba el uso de bloques de mármol de primer empleo para la talla de placas de sectile. En ese momento, predomina el gusto por las composiciones esquemáticas, casi siempre geométricas, con escasa variedad cromática, algo que a partir del reinado de Nerón se transformará

18. Estos esquemas compositivos con emblema central de opus sectile sobre cama de opus signinum se repiten también en la arquitectura doméstica de Carthago Nova (Soler, 2003 y 2005). 
a favor de esquemas más abigarrados y con el uso de mármoles de colores de diferentes procedencias (pórfido rojo, «serpentino», «pavonazzetto» y «giallo antico») (Pérez, 1996, 28).

En época flavia, pero sobre todo bajo Trajano y Adriano, los motivos se simplifican, se vuelve a realizaciones tradicionales, con motivos republicanos y materiales parcialmente marmóreos. A partir de finales del siglo II se ve en Hispania un cambio significativo que se afianzará durante todo el III e inicios del IV. La concordancia de los materiales queda olvidada para dar paso a conjuntos abigarrados en los que se busca el empleo del mayor número posible de tipos marmóreos. Esto se debe, en gran medida, a la prácticamente nula disponibilidad de bloques de primer empleo en este periodo, lo que provocará el uso casi exclusivo de piezas reutilizadas (Pérez, 1996, 46).

Todos estos datos nos podrían estar facilitando una cronología post $y$ ante quem para los ejemplares de 5-F. Serían posteriores al reinado de Nerón, es decir a partir de la segunda mitad del siglo I d. C., y anteriores a finales del siglo II d. C., cuando retornan modelos de diseño más complejo, lo que los coloca probablemente en época flavia, tal y como ocurre con otros elementos de la casa.

En cuanto a la pintura mural adscrita a esta vivienda (Fig. 11), la gran mayoría de los fragmentos documentados se hallaron en los niveles de derrumbe, aunque existe algún panel aislado que se localizó in situ y que nos permite definir en parte los diseños más utilizados. Hemos de añadir que en el sector 5-E, al oeste de la domus documentada en 5-F, se localizaron algunas estancias aisladas provistas de unos programas decorativos muy similares a los aparecidos en la vivienda del peristilo, sobre todo en lo que a la pintura mural se refiere, algo que unido a la proximidad de ambos sectores nos podría estar indicando que se trata de espacios pertenecientes a la misma casa altoimperial, ya que hemos de recordar que en la planta conocida de esta domus se intuye la existencia de otros espacios aún sin exhumar, tanto al oeste como al norte del sector.

Como podemos ver en la figura 12 , los esquemas compositivos representados en la pintura mural son básicamente tres, aunque destaca uno frente al resto, basado normalmente en un diseño con rodapié moteado, zócalo con imitación de mármol y una zona media de paneles anchos planos intercalados con paneles estrechos o interpaneles decorados con candelabros vegetales (Fernández, 2004, 171). Según las descripciones de los excavadores, las imitaciones de mármol pintadas en los zócalos de algunas de las paredes se caracterizaban por presentar bandas ondulantes oblicuas en color blanco, verde y negro o blanco, amarillo y negro; y ovas de diferentes tamaños pintadas en amarillo y algunas tonalidades rojizas. Es bastante complicado definir

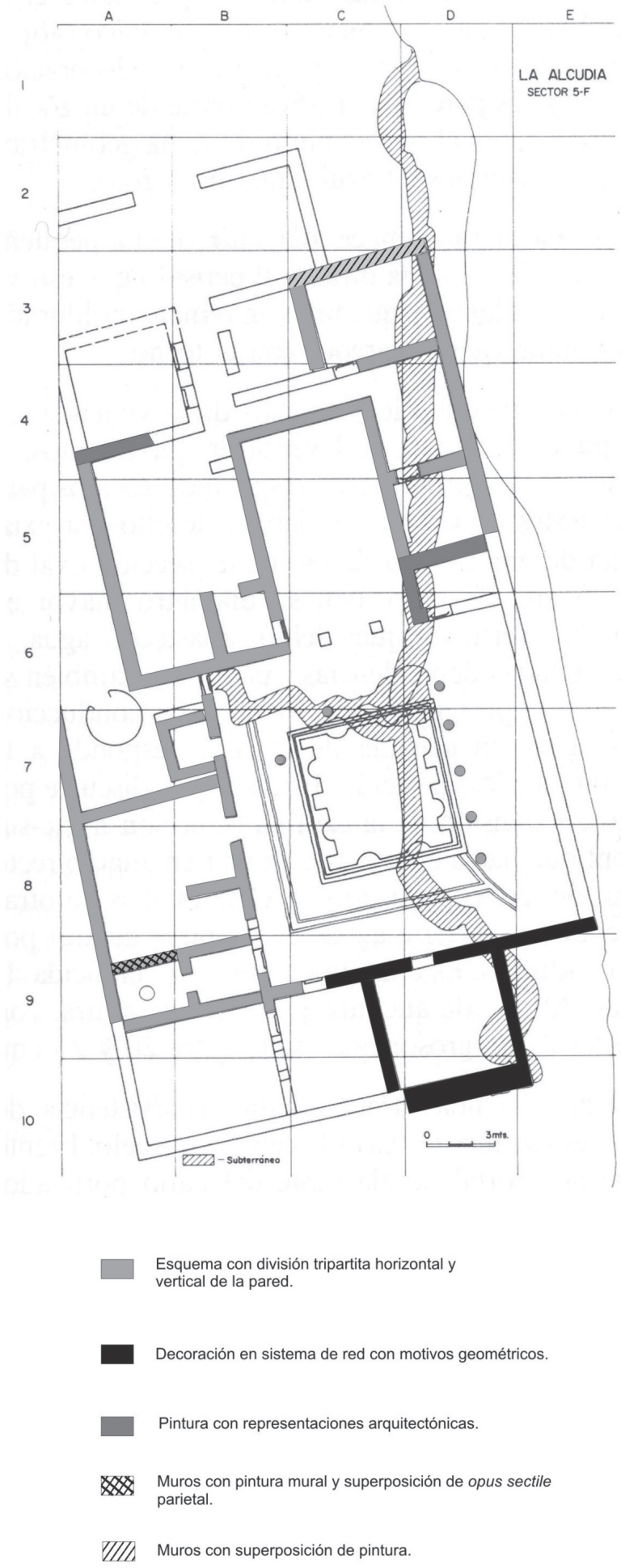

Figura 11: Planta de la domus en la que se marca la distribución de los esquemas compositivos de la decoración mural aparecidos.

el tipo de mármol representado en estos diseños, pero por las tonalidades y tipo de veta dibujada podrían adscribirse a los tipos «cipollino» o «pavonazzetto» en el primer caso y a variedades de «breccia» en el segundo (quizá un «giallo antico brecciato» o un «brocatello»), 
marmora de los que se han hallado algunos ejemplares en el yacimiento, sobre todo como soporte de sectilia, y que pudieron servir de inspiración a los artesanos.

Los otros dos esquemas documentados, de escasa representación, están basados en una decoración en sistema de red con motivos vegetales y geométricos (Fig. 13), y en pinturas con representaciones arquitectónicas. Del primer tipo destacan sobre todo los restos aparecidos en una de las habitaciones del sector 5-E y en la habitación 20 de la vivienda de 5-F. En el primer caso se halló un ejemplar fragmentado en el que se representa una sucesión de círculos secantes en rojo sobre fondo amarillo, con botón central con rosetas en color blanco, que A. Fernández Díaz atribuyó a la zona alta de la pared (Fernández, 2004, 172), mientras que la estancia 20, que se ha interpretado como el $t a-$ blinum, parece que estuvo decorada con un zócalo en negro, del que aún se conservan restos in situ, sobre el que se desarrolló un panel de rombos en azul, amarillo y rojo.

En cuanto al segundo tipo de esquema, con representaciones arquitectónicas, contamos con parte de la pintura del techo de una de las estancias de 5-E en la que se diseñó de forma bastante realista una cobertura con casetones en mármol y estuco que juegan con la sensación de claroscuro y la perspectiva (Abad, 1982, 32, fig. A.2.1.2.10.2e), recurso que caracteriza las representaciones del II estilo pompeyano; pero éstas, halladas en el mismo contexto que las imitaciones de mármol y los sistemas de red, más propios del IV estilo, parecen más tardías a las representaciones propias del II estilo (Fernández, 2004, 172).

Otros ambientes con representaciones arquitectónicas serían el 7 y el 12 del sector 5-F, donde se hallaron fragmentos de molduras de yeso que con toda probabilidad remataban las paredes interiores de estas estancias. Este tipo de decoración podría recordar al primero de los estilos pompeyanos, conocido también como estructural o de incrustaciones, en el que será frecuente el empleo de cornisas de estuco rematando los paneles. Sin embargo, el hecho de que aparezcan asociados a pintura mural propia del cuarto estilo las sitúa en el mismo contexto, explicándose como una pervivencia del gusto por el relieve desarrollado en los orígenes de la decoración pictórica mural.

En definitiva, podríamos resumir que el programa pictórico desarrollado en la domus, con preferencia por los esquemas tripartitos, se engloba en el conocido como cuarto estilo pompeyano, un estilo que toma elementos de los dos estilos anteriores, sobre todo las imitaciones marmóreas en los zócalos propias del segundo y los candelabros del tercer estilo. La cronología de este estilo, basada en los ejemplares de Pompeya, se sitúa desde mediados del siglo I d. C. hasta la erupción del Vesubio en el año 79 d. C., aunque fuera

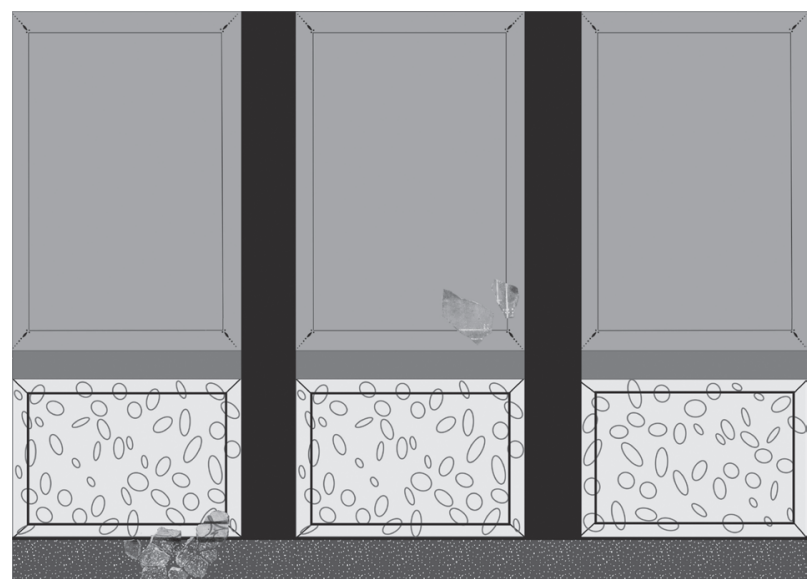

Figura 12: Panel mural con la restitución de lo que sería el esquema más representativo de los aparecidos en los contextos domésticos romanos de La Alcudia.

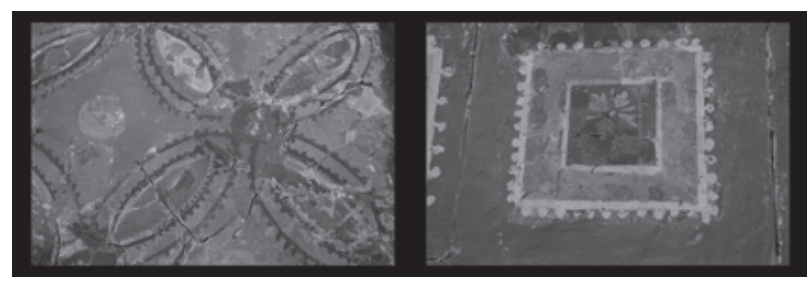

Figura 13: Pinturas murales con la representación de motivos en red y elementos arquitectónicos.

del contexto pompeyano, parece que se mantienen las características pictóricas que definen este estilo hasta la primera mitad del siglo II d. C. (Fernández, 2008, 181), por lo que los ejemplares de esta vivienda con imitación de moteados en los rodapiés, de mármol en los zócalos, paneles lisos y uniformes en la zona media, altamente representados en las casas pompeyanas, podrían fecharse a mediados del siglo I d. C., mientras que los sistemas en red de la zona superior, se corresponden más con decoraciones de mediados del siglo II d. C. (Fernández Díaz, 2004, 174).

No obstante, a pesar de que el programa pictórico original de la casa corrobora la cronología flavia atribuida por otros indicadores como los mosaicos o la propia estructura arquitectónica de la misma, se han constatado capas de pintura en muy mal estado de conservación cubriendo las originales (Fig. 14), lo que atestigua el uso continuado de la vivienda y el mantenimiento de los programas decorativos de la misma, que podría indicarnos una pervivencia del estatus socioeconómico del dominus más allá del siglo II d. C.

De entre todas esas habitaciones con refacciones murales, destaca la número 16 , un pequeño ambiente pavimentado con un emblema central de opus sectile y que fue interpretada como zona de baño. En la pared norte se conservaba in situ una pintura mural con un zócalo de color rojo con banda verde en la zona media 


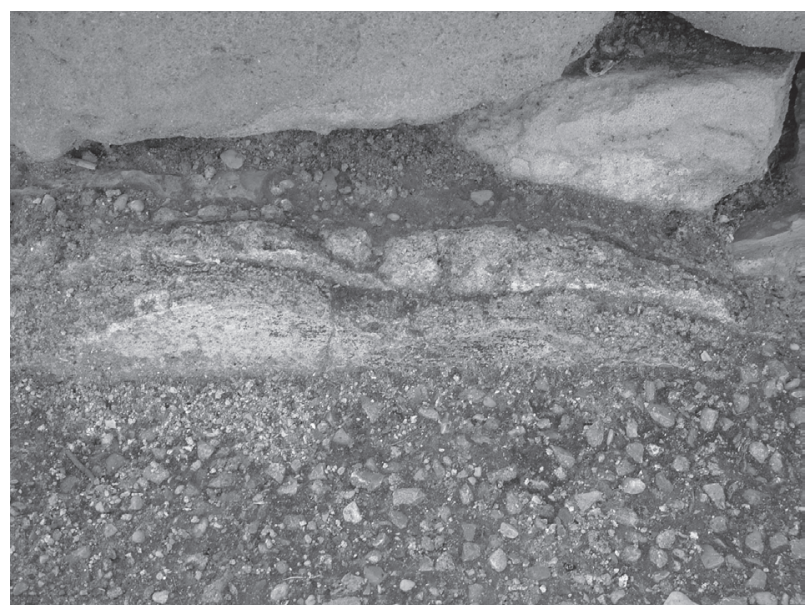

Figura 14: Detalle de las capas de pintura superpuestas, aún conservadas en alguno de los muros de la domus.

de la pared y un interpanel con la representación de arbustos verdes sobre fondo amarillo con rosas rojas y capullos de flor en blanco. Sobre ésta se detectó parte de un opus sectile parietal en el que apareció una placa de mármol fragmentada, una parte in situ y otra en el derrumbe, con la representación pintada en marrón de una pierna con sandalia. Este hecho nos podría estar indicando varias cosas, por un lado puede responder al intento por parte del propietario de dar una mayor importancia a este espacio, optando por el empleo de un revestimiento parietal marmóreo, que como sabemos es considerado como un soporte más suntuoso; sin embargo, podría haberse realizado únicamente para revestir el zócalo ya que, al tratarse de una zona de baño, esta parte de la pared es la que con mayor facilidad suele deteriorarse por la humedad. Además, suele ser bastante difícil encontrar paredes revestidas únicamente con opus sectile, recurso que en la mayoría de las ocasiones convive con la pintura en el mismo lienzo.

Otro dato a destacar es que este nuevo revestimiento no incluye un verdadero trabajo compositivo a base de placas de diferente variedad cromática, algo habitual en este tipo de obra, supliendo la falta de marmora diversos con una escena pintada sobre el placado liso. Esta técnica ornamental no es muy habitual en los opera sectilia ya que la finalidad de éstos era crear verdaderos cuadros con representaciones figurativas o geométricas realizadas con placas de diferentes colores que imitaran los estilos pictóricos pero introduciendo un material más noble a la decoración.

Es probable entonces que el artesano que decoró esta estancia revistiéndola con un sectile parietal no contara con la capacidad técnica o, lo que es más probable, con los recursos económicos necesarios para componer un diseño marmóreo canónico, de ahí que el acabado escenográfico fuera pintado sobre el sectile.

La cronología de estas reformas es muy difícil de establecer, ya que tradicionalmente se había propuesto un segundo momento de auge urbanístico y privado, con nuevas reformas en las casas, en el último tercio del siglo III d.C. y primera mitad del IV d. C., coincidiendo con las supuestas invasiones francas (Ramos Fernández, 1991, 73) pero ya sabemos que en el registro estratigráfico con el que contamos no se documentan, materialmente hablando, algunos de los hitos históricos atribuidos a la ciudad de Ilici, por lo que no resulta posible concretar desde esta base las fechas de esas reformas.

No obstante, a nivel estilístico sí parece constatarse un segundo momento de auge en los programas decorativos de los ambientes domésticos de La Alcudia a finales del siglo III d.C., con una pintura mural de diseños más anárquicos (Fernández, 2004, 174) y la aparición de pequeñas placas geométricas y figurativas de diferente procedencia que indican el uso frecuente de opera sectilia de cronología tardía, caracterizados por el reempleo de material marmóreo y por composiciones decorativas abigarradas.

\section{LAS HABITACIONES DE LA CASA}

Una vez visto, tanto la estructura arquitectónica de la domus como los programas decorativos documentados en la misma, sería interesante ver hasta qué punto es posible atribuir una $u$ otra funcionalidad a cada una de las habitaciones que conforman la vivienda altoimperial y si se trata de una planta que cumple con las formas canónicas de una típica casa romana.

Lo primero que hay que indicar es que el hecho de que aparezcan estancias con programas decorativos similares en un sector cercano al 5-F, nos lleva a pensar que la vivienda contó con una mayor extensión de la que conocemos en la actualidad, al menos al norte, este y oeste de los restos exhumados.

Según sus excavadores se ingresaba por el norte desde la calle, dando paso a una gran sala (la número 1) de 4,60 m por $12 \mathrm{~m}$, aunque es probable que la entrada principal no fuera esta ya que como decíamos se supone la existencia de más dependencias hacia el norte, a lo que se añade la propia espacialidad de esta primera sala, que no guarda una proporción propia de las fauces o del vestíbulo de una domus romana ${ }^{19}$. Ellos hablan de que se podría articular otro peristilo al norte al igual que ocurre en el sector 3-F, pero eso nos dejaría muy poco margen de separación entre ambas casas, reduciendo demasiado el espacio de la calle. A continuación, el ambiente 5 fue interpretado como un vestíbulo, aunque en realidad parece más un corredor,

19. Esta suele ser la opción más frecuente aunque no podemos olvidar que existen algunos ejemplos de casas pompeyanas donde el ingreso se realiza directamente a una sala de notables dimensiones (vestíbulo-atrio). 
pavimentado con argamasa y con portales de sillería en los umbrales de las dos estancias a las que da acceso.

En términos generales, la mayoría de estancias podrían corresponder a cubicula o estancias privadas de reposo, ya que casi todas ellas presentan las dimensiones y la decoración propia de este tipo de habitaciones. Sin embargo, son de destacar dos ejes fundamentales dentro de una vivienda y que en este caso parecen identificarse con bastante claridad.

Nos referimos por un lado al eje de representación, de carácter más público, y al eje de servicios, cuyas estancias suelen agruparse en una de las zonas de la casa.

Del primer eje ya hemos hablado anteriormente cuando describíamos la arquitectura de la casa, y como decíamos la adscripción dada por los excavadores a las salas 9 y 20 parece ser la más adecuada. La primera fue interpretada como el triclinium o comedor de la casa, ya que en los niveles de destrucción de la misma se documentaron algunas dovelas decoradas con motivos vegetales y parte de dos pilares de ladrillo in situ con fragmentos de pilastras molduradas en los derrumbes. Estos restos presuponen una arquería doble de acceso desde el peristilo, y como es bien conocido, las salas de recepción se distinguen muchas veces por su amplitud, su arquitectura y su decoración; por lo que la importancia del lugar se subraya en ocasiones mediante accesos monumentales con tres huecos que facilitan la accesibilidad de los comensales (Thébert, 1987, 354).

Suele tratarse de la sala más amplia y suntuosa y juegan un papel muy importante en la arquitectura de la casa, puesto que el dueño tiene el deber de recibir a menudo y con esplendidez, en particular durante las comidas, y no hay casa noble que no disponga de uno o más comedores.

Además de por su ubicación y dimensiones, la identificación de esta habitación queda facilitada en ocasiones por el diseño del mosaico; mientras que el espacio central se adorna con motivos escogidos, el emplazamiento de los lechos dispuestos a lo largo de los muros y destinados a acoger a los comensales suele aparecer con una decoración más sencilla, algo que en el caso que nos ocupa no parece cumplirse del todo ya que aunque no conservamos todo el pavimento musivo, parece que el desarrollo de la alfombra fue realizado con teselas blancas y orla de enmarque geométrica en negro.

El otro espacio de representación, el tablinum, fue atribuido a la habitación 20, que como ya explicábamos fue «deconstruida» en las labores de consolidación, forzando un acceso parecido al del triclinium para darle un carácter más monumental a la sala. La funcionalidad del tablinum es bien conocida, hacía las veces de despacho del propietario y por lo tanto era también un lugar frecuentado por gentes externas a la casa.
El segundo eje al que nos referíamos es el de servicios, formado por los espacios de cocina, baño y letrinas de la vivienda, y que normalmente se ubican agrupados en la parte de la casa más cercana a los conductos de agua y calefacción. En la domus 5-F se identificó como culina (cocina) la habitación 14, ya que en ésta se encontró parte de lo que parecía un horno de pan de planta circular realizado con adobes. Esta interpretación resulta bastante lógica, aunque pensamos que de ser cierta la identificación de esa estructura circular con un horno de pan, lo más probable es que esta estancia no estuviera cubierta, que fuera un espacio abierto desde el que también se accedía a la galería sanitaria, cuyo acceso fue abierto bajo la cota de uso del cierre oriental de este ambiente, por lo que es probable que la cocina estuviera en la habitación contigua, la 15 , la cual apareció pavimentada con un opus caementicium.

Al sur de ésta se levantaron dos pequeñas salas, la 16 y 17 , que se interpretaron como el baño y las letrinas de la casa respectivamente, ya que pegada al muro meridional de las mismas aparecieron restos de una tubería de plomo que probablemente abriera al canal de desagüe construido bajo el pavimento del peristilo y que indica el uso frecuente de agua en estas salas.

No se han detectado sistemas de calefacción (hypocausta o concamerationes) por debajo de los suelos o en las paredes de la vivienda, así como tampoco praefurnia que permitieran la alimentación de calor, al menos a estas estancias de baño, algo que no resulta del todo extraño si tenemos en cuenta que la mayoría de estas domus se construyen cuando aún no se había desarrollado el gusto por los balnea privados (los cuales sí requerirán una infraestructura termal apropiada) en detrimento de los grandes conjuntos termales urbanos, de los que en Ilici existen dos grandes ejemplos de la misma época que dichas domus, lo que nos indica todavía un uso frecuente de los baños públicos en ese momento.

\section{EL FINAL DE LA DOMUS ROMANA}

Por último, nos gustaría detenernos un momento en la evolución final sufrida por esta vivienda durante el periodo comprendido entre los «estratos» A y B, definidos por los excavadores de este sector como los estratos formados desde finales del siglo III d.C. (B) hasta época visigoda (A). Como ya hemos podido comprobar en el discurso expuesto anteriormente, existe una gran dificultad en el análisis interpretativo de las estructuras plenamente romanas que conformaron la vivienda altoimperial, debido en gran medida a las evidentes carencias del registro arqueológico y a las continuas restituciones idealizadas de los restos fosilizados en el sitio. Sin embargo, esta dificultad se vuelve más acuciante en el caso de los restos estruc- 


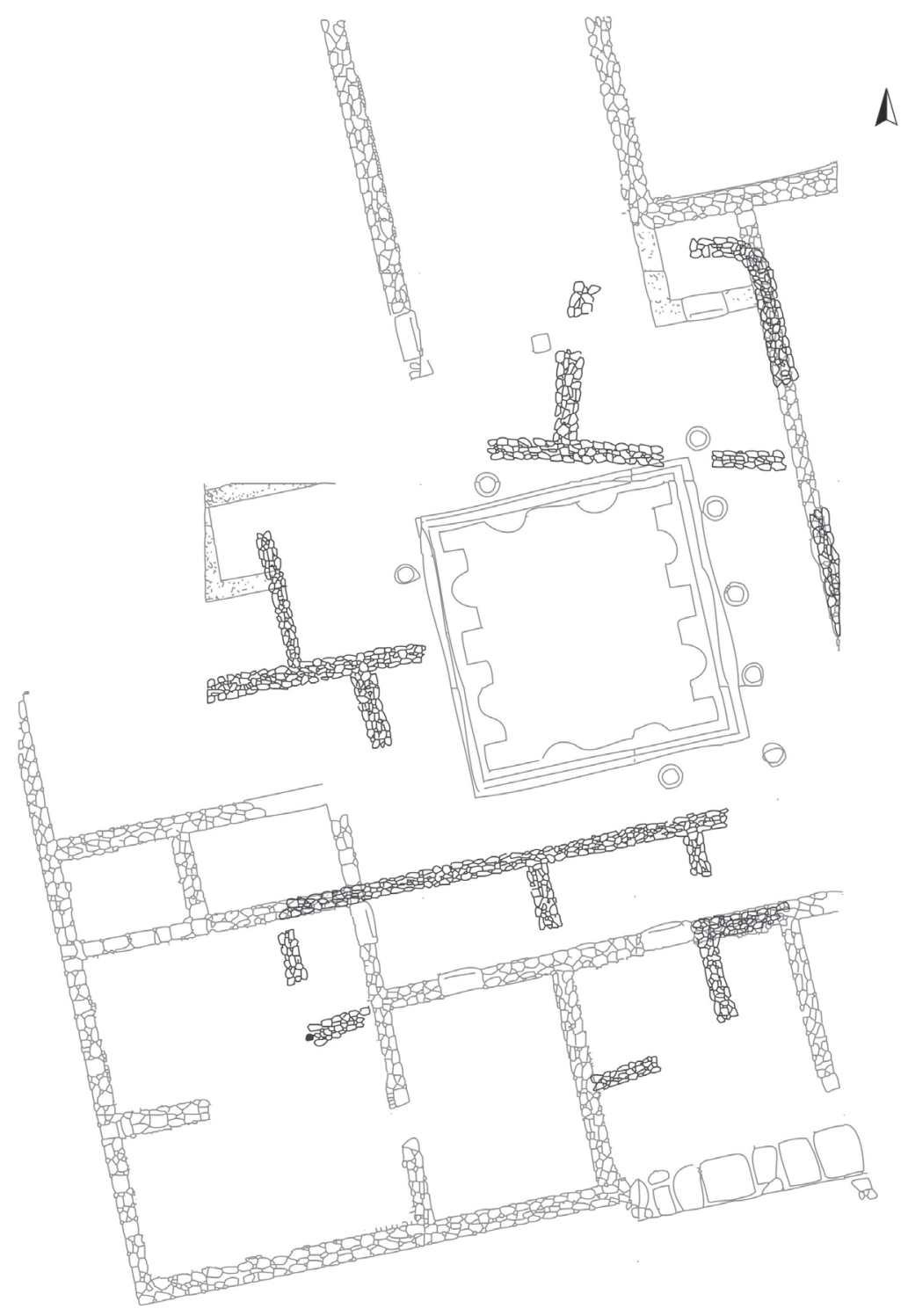

Figura 15: Planta de la domus 5-F con la superposición de las estructuras visigodas levantadas sobre la misma.

turales más tardíos que se documentaron amortizando los plenamente romanos ya que, además de haber sido desmontados tras su exhumación, la historiografía tradicional del yacimiento obvió en la mayoría de las ocasiones los datos relativos a la sede episcopal de Ilici a favor de un mayor conocimiento de la colonia romana, lo que ha provocado un gran desconocimiento de la trama urbana tardorromana y altomedieval de la ciudad, sobre todo en lo que a los ambientes domésticos se refiere, dándole importancia exclusivamente a las ruinas más monumentales de este momento, como es el caso de la basílica cristiana reconstruida al suroeste del yacimiento.

Es cierto que en las memorias de excavación del sector 5-F se hace referencia a la aparición de una serie de lienzos y pavimentaciones que en parte remontaban algunos de los muros de cronología anterior, tanto de la fase republicana como de la altoimperial ${ }^{20}$, y que se adscriben a un periodo comprendido entre el siglo $\mathrm{V}$ y el VIl, pero únicamente contamos con una descripción muy somera de dichas estructuras. Se habla de muros con aparejo de cantos rodados, piedra de mediano y pequeño tamaño, y material cerámico de construcción reempleado. En cuanto a los niveles de uso asociados parece que los pavimentos eran de cal sobre tierra apisonada y de tierra batida endurecida (Ramos Fernández, 1983, 147) (Fig. 15).

20. Recordamos que algunos de esos remontes resultaban algo incoherentes, ya que existían muros de cronología visigoda cimentados sobre lienzos republicanos que en época imperial no se veían, por lo que la única explicación posible sería que durante la construcción de época visigoda se zanjeara el sector sacando a la luz estructuras de los siglos II y I a. C. 
De la planimetría existente sobre esta fase constructiva se puede extraer que las estructuras conforman nuevas estancias de habitación o compartimentan las ya existentes desfigurando en gran medida la planta previa, aunque suponemos que la casa en este momento presentaría ya un aspecto bastante deteriorado. Los espacios visigodos se articularán en torno al peristilo de la antigua domus, siguiendo en mayor o menor medida la orientación de éste, conformando lo que pensamos serían varias unidades domésticas alrededor de un ambiente abierto común. Este fenómeno será muy característico en los momentos finales del mundo antiguo y en todo el alto medievo, donde primará un nuevo concepto de rentabilidad arquitectónica frente a la organizada y espaciosa propiedad privada romana. Se optará por una fragmentación de los antiguos complejos domésticos creando viviendas unifamiliares de una o dos estancias que compartirán patio con otras unidades domésticas (Gutiérrez, 2004, 107).

El caso de la domus 5-F es muy similar a lo ocurrido en otras domus de ciudades romanas con continuidad urbanística en época altomedieval, como ocurre con un ejemplo de Mérida, donde una de las casas romanas de grandes dimensiones se convertirá en un entramado vecinal formado por varias viviendas articuladas alrededor del peristilo (Alba, 1997).

Por tanto, una labor primordial en el futuro de las investigaciones de La Alcudia sería el estudio de la posible trama urbana de época visigoda conservada sobre la solera de las edificaciones públicas ${ }^{21}$ y privadas que conformaron la colonia romana, en un intento por contextualizar aquellos espacios más monumentales bien conocidos dentro del conjunto habitacional propio de una ciuitas visigoda, caracterizada tanto por los edificios administrativos y de culto que le son propios - no hemos de olvidar que en el caso de las sedes episcopales como Ilici el territorium al que administraban solía ser muy extenso- como por las viviendas de sus pobladores, las cuales han sido vistas por la historiografía tradicional como conjuntos aislados más propios del mundo rural que de una autentica ciudad.

Julia Sarabia Bautista
Área de Arqueología
Dpto. Prehistoria, Arqueología, Ha Antigua,
Filología Griega y Filología Latina
Facultad de Filosofía y Letras
Universidad de Alicante
03080 Alicante
julia.sarabia@ua.es

21. Parece que lo ocurrido en el sector de la domus 5-F también se ha detectado sobre edificios de carácter público como las termas orientales, donde sobre la sala meridional de las mismas se alzaban cuatro muros de ladrillo, que compartimentaron esta sala en cinco estancias rectangulares, aunque no podemos asegurar su carácter doméstico (Abad, e.p.).

\author{
Víctor Cañavate Castejón \\ Parque Arqueológico Tolmo de Minateda \\ victor.canavate@ua.es
}

\section{BIBLIOGRAFÍA}

ABAD CASAL, L. 1982: La pintura mural romana en España, Sevilla-Alicante.

ABAD CASAL, L. 1986-1987: «En torno a dos mosaicos ilicitanos: el helenístico y el de conchas marinas», Cuadernos de Prehistoria y Arqueología de la UAM (Homenaje a Gratiniano Nieto, II), 13-14, 97-105, Madrid.

Abad CASAl, L. 1989: «El mosaico romano en el País Valenciano: los mosaicos de opus signinum», Mosaicos romanos. In memoriam M. Fernández-Galiano, 159-167, Madrid.

Abad CASAL, L. 2004: «La Alcudia Ibérica: en busca de la ciudad perdida», Catálogo de la exposición Iberia, Hispania, Spania. Una mirada desde Ilici, 69-78, Alicante.

ABAD CASAl, L., e.p.: «La Alcudia de Elche (Alicante). Ayer y hoy de un yacimiento emblemático».

Abad Casal, L., Moratalla Jávega, J. y Tendero Porras, M. 2000: «Contextos de Antigüedad Tardía en las termas occidentales de La Alcudia (Elche, Alicante)», AnMurcia, 16, 133-147.

ADAM, J-P. 2008: La Construction romaine, París.

Alba Calzado, M. 1997: «Ocupación diacrónica del Área Arqueológica de Morería (Mérida)», Mérida. Excavaciones Arqueológicas, 1994-95, Memoria I, 285-315, Mérida.

ALFÖLDY, G. 2003: «Administración, urbanización, instituciones, vida pública y orden social», Canelobre 48, 3557.

ANDRÉs, G. et alii 2002: Así era la vida en una ciudad romana, Calagurris Iulia, Calahorra.

CARANDINI, A. 1989: «La villa romana e la piantagione schiavista», Storia di Roma. Caratteri e morfologie, 4, 101200.

CORell, J. 1999: Inscripcions romanes d'Ilici, Lucentum, Allon, Dianium i els seus respectius territoris, Valencia.

EsCRIVÀ CHOVER, M. I. 2005: Basas romanas de la provincia Tarraconensis, Valencia.

FERNÁNDEZ CASADO, C. 1983: Ingeniería hidráulica romana, Madrid.

Fernández DíAz, A. 2000: El programa pictórico de los edificios públicos y privados del Área de Carthago Noua y su entorno. Tesis Doctoral inédita. Universidad de Murcia.

Fernández DíAz, A. 2003: «Adopción de las técnicas pictóricas y musivarias entre las sociedades íberas», Actas del Seminario de Arqueología De Iberia in Hispaniam. La adaptación de las sociedades ibéricas a los modelos romanos (Soria, 2001), 207-239, Alicante.

FERnÁndeZ DíAZ, A. 2004: «Los programas ornamentales. Pintura y mosaico», Catálogo de la exposición Iberia, Hispania, Spania. Una mirada desde Ilici,167-174, Alicante.

FERNÁNDEZ DíAz, A. 2008: La pintura mural romana de Carthago Noua. Evolución del programa pictórico a través de los estilos, talleres y otras técnicas decorativas, Murcia.

Ferreruela A., Mesa, J. F., Mínguez, J. A. y Navarro, M., 2003: «Una inscripción republicana de la sede de una 
posible corporación en La Cabañeta (El Burgo de Ebro, Zaragoza): nuevos datos sobre la ocupación romana del Valle del Ebro», AEspA, 76, 217-230.

Gómez Pallarès, J. 1997: Edición y comentario de las inscripciones sobre mosaico de Hispania. Inscripciones no cristianas, Roma.

GuIDOBALDI, F. 1985: «Pavimenti in opus sectile di Roma e dell'area romana: proposte per una classificazione e criteri di datazione», en P. Pensabene (ed.), Marmi Antichi, Studi Miscellanei, 26, 171-251, Roma.

Gutiérrez Lloret, S. 1996: La Cora de Tudmîr: de la antigüedad tardía al mundo islámico. Poblamiento y cultura material, Madrid.

Gutiérrez Lloret, S. 2004: «Ilici en la Antigüedad Tardía. La ciudad evanescente», Catálogo de la exposición Iberia, Hispania, Spania. Una mirada desde Ilici, Alicante, 95-110.

IBARRA RuIz, P. 1926: Elche, materiales para su historia. Ensayo demostrativo de su antigüedad e importancia histórica, Cuenca.

Hernández Ramírez, J. 1998: «Las cloacas de Emerita Augusta», Ciudades históricas vivas, ciudades del pasado: pervivencia y desarrollo, Mérida.

LARA Vives, G. 2005: El culto a Juno en Ilici y sus evidencias, Villena.

Lara Vives, G. 2007: «Nuevos datos para la contextualización del mosaico helenístico de La Alcudia (Elche, Alicante)», Actas Congreso Arte Ibérico en la España Mediterránea (Alicante 24-27 octubre 2005), 155-166, Alicante.

Lorenzo Pérez de SAn RomÁn, R. 2006: L'Alcúdia d'Elx a l'antiguitat tardana. Anàlisi historiogràfica i arqueològica de l'Ilici dels segles V-VIII, Alicante.

Luengo, J. M. 1955: «Astorga (León), exploración de las cloacas romanas», Noticiario Arqueológico Hispanico, II, 1-3, 143-152.

Lugl, G. 1968: La tecnica edilizia romana, Roma.

Muñoz OJeda, F. J. y SARabia Bautista, J. 2000: «Aportación a los estudios sobre el uso de mármoles locales en el Sureste Peninsular. La Alcudia de Elche (Alicante)», AnMurcia, 16, 169-185.

PAdRos Martí, P. 1998: «El suministro de agua y la red de colectores en la ciudad romana de Baetulo», Los orígenes de la ciudad en el Noroeste Hispánico, Lugo.

Pérez Olmedo, E. 1996: Revestimientos de Opus Sectile en la Península Ibérica, Studia Archaeologica, 84. Valladolid.

Ramallo Asensio, S. F. 1990: Talleres y escuelas musivas en la Península Ibérica, en Mosaicos romanos: estudios sobre iconografia (in Memoriam de Alberto Balil), 135 180, Valladolid.
Ramallo Asensio, S. F. 1995: «La Villa de la Quintilla (Lorca): una aproximación a su proyecto arquitectónico y al programa ornamental», en J. M. Noguera CELDRÁN (coord.), Poblamiento rural romano en el sureste de Hispania, 49-80, Murcia.

Ramos Fernández, R. 1975: La ciudad romana de Illici, Alicante.

Ramos Fernández, R. 1983: «Estratigrafía del sector 5-F de La Alcudia de Elche», Lucentum, II, 147-172.

RAmos Fernández, R. 1989: «Nuevos hallazgos en La Alcudia de Elche», AEspA, 62, 236-240.

Ramos FernÁndez, R. 1991: «La casa urbana hispanorromana en Illici», I Coloquio Internacional sobre La casa urbana hispanorromana. Ponencias y comunicaciones, 69-78, Guadalajara.

Ramos Folqués, A. 1956: «Memoria de las excavaciones practicadas en La Alcudia de Elche. Campañas 1949 a 1952», Noticiario Arqueológico Hispánico, III y IV, 1/3, 1954-1955, 102-113.

Ramos Folqués, A. 1962a: «Excavaciones en La Alcudia», Noticiario Arqueológico Hispánico, 5, 1956-1961, 9197.

Ramos Folqués, A. 1962b: «Estado actual de las excavaciones en La Alcudia de ELche», VII Congreso Nacional de Arqueología, Barcelona 1960, 273-277, Zaragoza.

Ramos Folqués, A. 1966: «Estratigrafía de La Alcudia de Elche», Saitabi, XVI, 71-76.

Ramos Folqués, A. 1975: «Un mosaico helenístico en La Alcudia de Elche», Archivo de Prehistoria Levantina, XIV, 69-81.

Ramos Molina, A. 1997: La planimetría del yacimiento de La Alcudia de Elche, Alicante.

RodÁ DE LlANZA, I, 1997: «Los mármoles romanos de Hispania», Histria Antiqua, 3, 47-56.

Sala Sellés, F. 1992: La tienda del alfarero del yacimiento de La Alcudia, Alicante.

SOler Huertas, B. 2003: «Algunas consideraciones sobre el empleo privado del mármol en Carthago Nova», Mastia, 2, 149-187.

Soler Huertas, B. 2005: «Hacia una sistematización cronológica sobre el empleo del marmor y su comercialización en Carthago Nova», Mastia, 4, 29-64.

Tammisto, A. 1997: Birds in mosaics. A study on the representation of birds in Hellenistic and Romano-Campanian Tesselated Mosiacs to the Early Augustan Age, Acta Instituti Romani Finlandiae, XVIII, Roma.

THÉBERT, Y. 1987: «Vida privada y arquitectura doméstica en el África romana», Historia de la vida privada. Del imperio romano al año mil, 305-402, Madrid. 